\title{
The Influences of Participation in an Elite Paralympic Military Program on the Self-Identity of Active Duty Service Members with Acquired Disabilities
}

\author{
Lindsay M. Hammond
}

Follow this and additional works at: https://researchrepository.wvu.edu/etd

\section{Recommended Citation}

Hammond, Lindsay M., "The Influences of Participation in an Elite Paralympic Military Program on the Self-Identity of Active Duty Service Members with Acquired Disabilities" (2015). Graduate Theses,

Dissertations, and Problem Reports. 5744.

https://researchrepository.wvu.edu/etd/5744

This Dissertation is protected by copyright and/or related rights. It has been brought to you by the The Research Repository @ WVU with permission from the rights-holder(s). You are free to use this Dissertation in any way that is permitted by the copyright and related rights legislation that applies to your use. For other uses you must obtain permission from the rights-holder(s) directly, unless additional rights are indicated by a Creative Commons license in the record and/ or on the work itself. This Dissertation has been accepted for inclusion in WVU Graduate Theses, Dissertations, and Problem Reports collection by an authorized administrator of The Research Repository @ WVU.

For more information, please contact researchrepository@mail.wvu.edu. 
The Influences of Participation in an Elite Paralympic Military Program on the SelfIdentity of Active Duty Service Members with Acquired Disabilities

\author{
Lindsay M. Hammond, M.S. \\ Dissertation submitted to the College of Physical Activity \\ and Sport Sciences at West Virginia University \\ in partial fulfillment of the requirements for the degree of
}

Doctor of Philosophy

In

Coaching and Teaching Studies

\author{
Kristen Dieffenbach, Ph.D., Chair. \\ Emily Jones, Ph.D. \\ Aaron Moffett, Ph.D. \\ Andrea Taliaferro, Ph.D. \\ Valerie Wayda, Ed.D.
}

College of Physical Activity and Sport Sciences

Morgantown, West Virginia
2015

Keywords: active duty service members, acquired disability, sport, identity Copyright 2015 Lindsay Hammond 


\section{ABSTRACT \\ The Influences of Participation in an Elite Paralympic Military Program on the Self-Identity of Active Duty Service Members with Acquired Disabilities}

\section{Lindsay M. Hammond, M.S.}

Background/Purpose: To explore the lived experiences of active duty service members with acquired disabilities that participated in an elite military sport program to gain an enhanced perspective on how elite sport programming influences self-identity post injury. Methods: A phenomenological approach was employed, using a three phase semistructured interview protocol to capture military journeys of four (4) service members who had sustained a physical disability as the result of a combat injury and chose to remain on active duty status as a part of a specialized unit designed to prepare service members for the Paralympics. Results: Three themes were identified with implications on the saliency of the service members' identities. These were (a) goal orientation, (b) champions through transition, and (c) the unit. Participants reported that participation in the specialized unit provided new challenges and opportunities, inspired both athletic and military goals and provided the opportunity to continue to serve. Conclusion: Concepts self-determination theory (STD) were evident across the participants' accounts of their military careers. The findings portray a group of highly self-determined service members, who throughout the course of their military journey experienced a strong sense of competence, relatedness and autonomy. The elite military sport program provided infrastructure required to foster the salience of a service member identity. 


\section{Dedications}

There are few moments in life when you have the opportunity to formally recognize the people who have inspired your personal journey and give thanks to those who have supported you along the way. It is with great pleasure to write this dedication after an epic four-year journey. This dissertation is dedicated to my late grandfather Robert (Bob) Brooke, who always encouraged me to follow my heart, take chances, pursue my passion, and love life. Although he passed before this new chapter began, he has been with me in spirit through the highs and lows of this pursuit, pushing me to reach the finish line. 


\section{Acknowledgements}

This dream began long ago, but it would never have come to fruition without the support and encouragement of my family, friends and professors. Firstly, I am incredibly grateful for my husband Jon, who encouraged me to take a leap of faith, leave my established career in Colorado and move 1300 miles to Morgantown, West Virginia to begin a new chapter. He has been my rock through this process, keeping me grounded during my moments of uncertainty and cheering me on when I wanted to quit. To my parents, Warren and Doris Brooke who believed in this dream at times more than I did! Dad, you lit the fire some twenty odd years ago and I haven't looked back. Thank you so much for believing in me and always encouraging me to achieve my goals. To my Brazilian sister Luciana, where would I be without you? Your crazy intensity and love of life has been truly inspiring. And to my laid back friend Philip Liversedge, your lighthearted nature and sarcasm got us through some of the most challenging of times. Thank you both for your support, guidance and most importantly your friendship.

I would also like to express my sincerest gratitude to my committee members. It has been a pleasure working with each of you and I can't thank you enough for helping me bring this research idea come to life. I will forever be grateful for your vision, insightful thoughts and continuously challenging me throughout this process. Dr. Kristen Dieffenbach, you have been my champion from day one, always encouraging me to follow my own path. Thank you for your guidance and support and understanding of my personal distractions (wedding, baby, etc.) throughout the last four years. Dr. Andrea Taliaferro, thank you for your willingness to mentoring me through so many wonderful research adventures and your patience when it came to my tardiness with deadlines. Dr. 
Wayda, your positivity has always been refreshing and encouraging. Thank you for always being available as a sounding board for all of my questions and concerns. Dr. Moffett, I am so grateful that you agreed to sit on my committee. Your expertise in this area is second to none and I very much appreciate you taking the time to be apart of this project. Finally, Dr. Jones, my qualitative specialist. I can't thank you enough for jumping on board and sharing your knowledge with me. 


\section{Table of Contents}

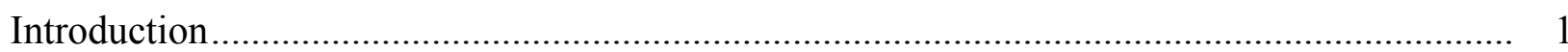

Statement of the Problem..................................................................................... 7

Research Questions .................................................................................. 8

Definition of Terms ..................................................................................... 8

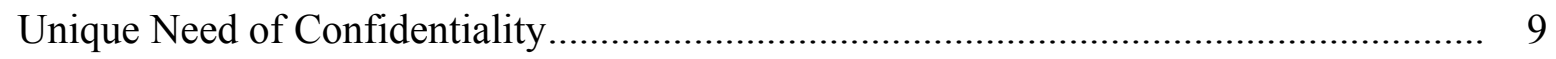

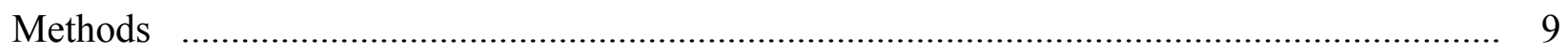

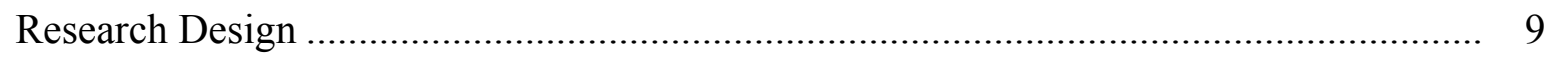

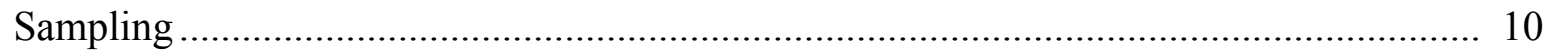

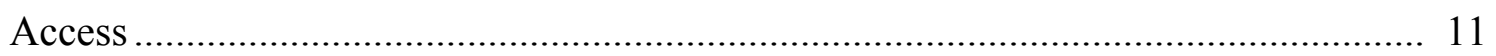

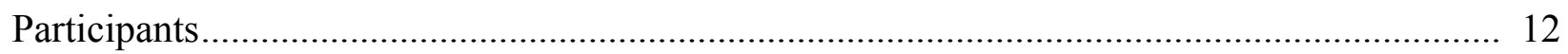

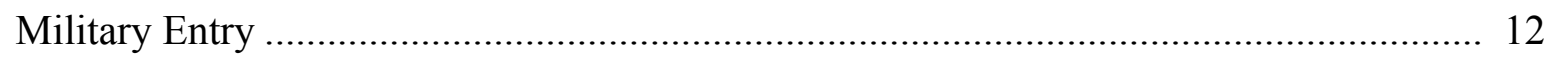

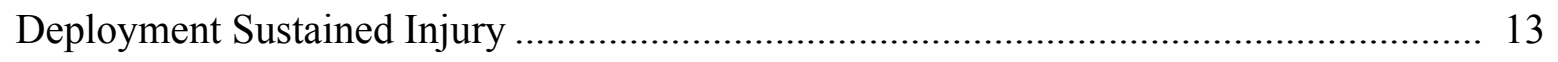

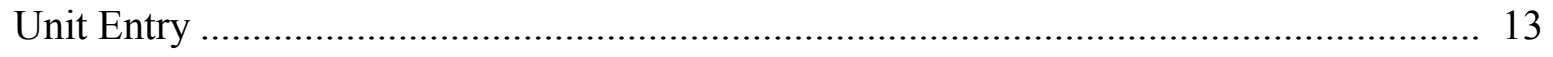

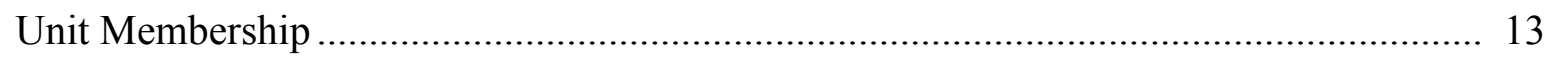

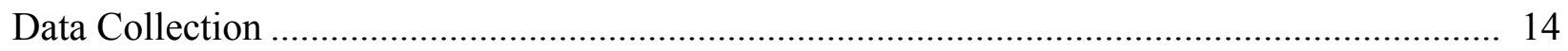

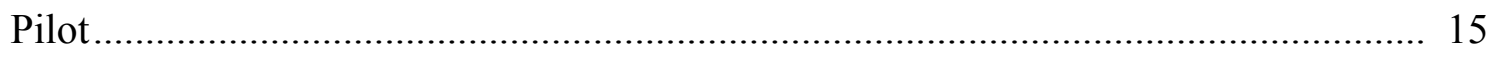

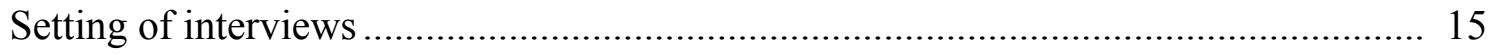

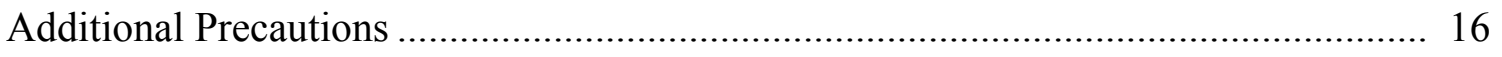

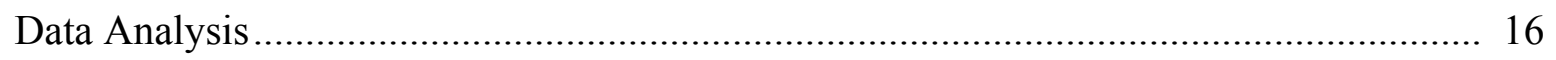

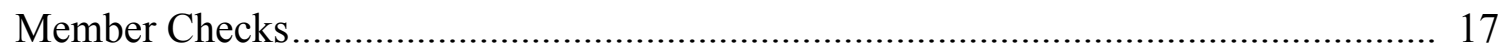

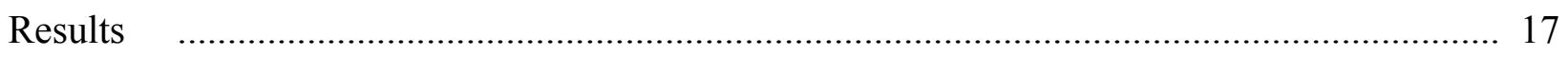

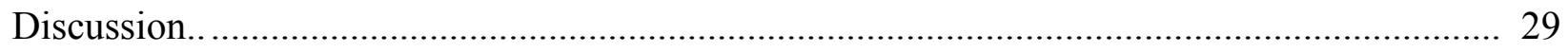




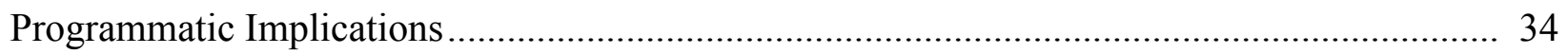

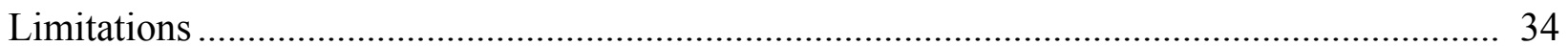

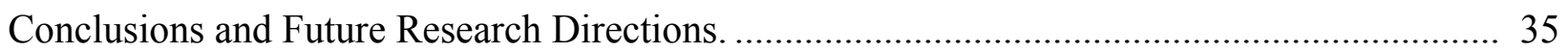

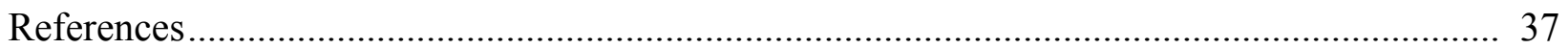

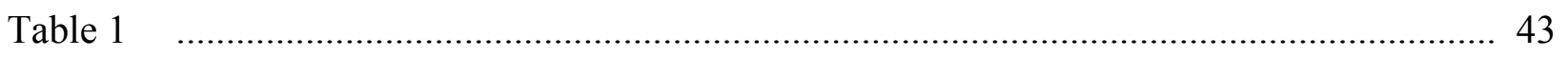

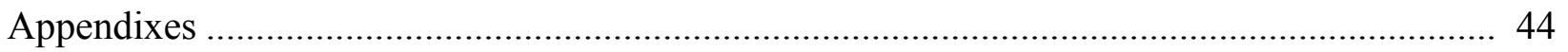

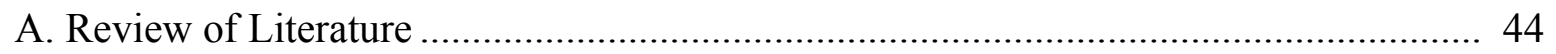

Identity of U.S. Service Members .......................................................................... 44

Formation of Military Service Member Identity .................................................... 46

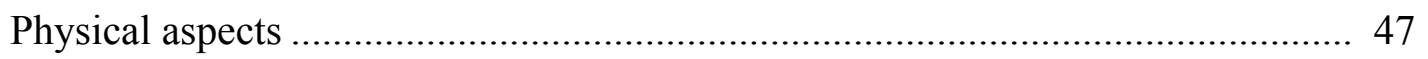

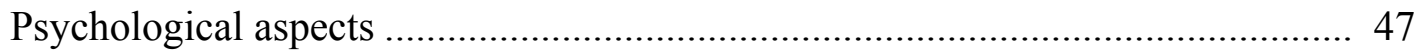

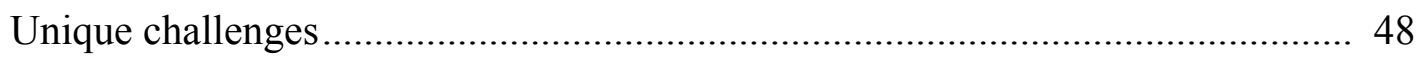

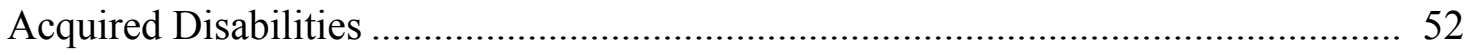

Psychological implications ........................................................................... 52

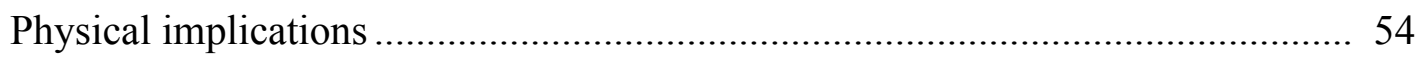

Military initiatives for veterans with acquired disabilities ....................................... 55

Recovery Through Sport: Benefits of Participation ................................................. 56

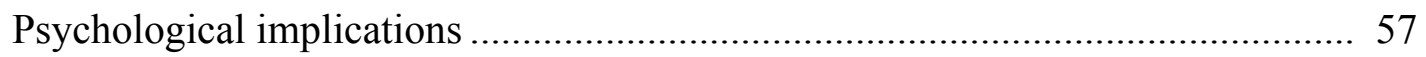

Post-traumatic growth and resilience............................................................... 57

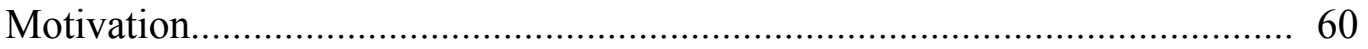

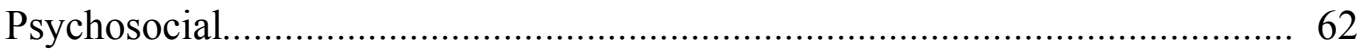

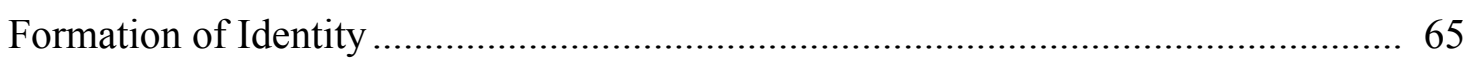

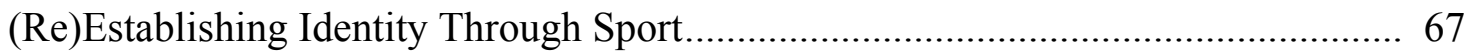


Summary

References. 75

B. Recruitment Script 1: Invitation to Participate Letter .................................................. 86

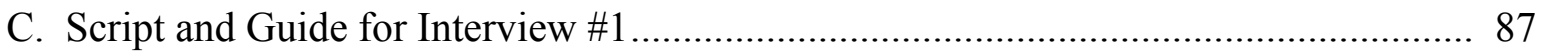

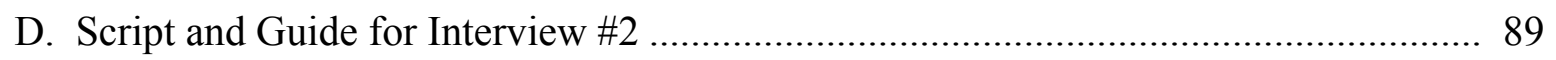

E. Script and Guide for Interview \#3 ……………….............................................. 91

F. Recruitment Script 2: Invitation to Participate E-Mail............................................... 93

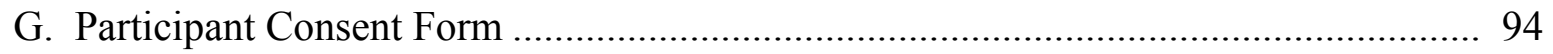




\section{The Influences of Participation in an Elite Paralympic Military Program on the Self-Identity of Active Duty Service Members with Acquired Disabilities}

The evolution of the United States Armed Forces (USAF) infrastructure since the days of the draft has inevitably influenced the change in culture and the identity of its service members. Although historically, a required service and considered one of the most dangerous professions, as of 2015 more than 1.4 million people are presently volunteering to serve their country in uniform (Defense Manpower Data Center, 2015). In the shadow of September 11, 2001, enlistment reached an all-time high, with many individuals trading their professions for public service (Kingsbury, 2010). Individuals enlist for a variety of reasons from patriotism to job security and each voluntarily abandons their civilian identity for assimilation required to honor the military uniform. In his inaugural address, President Obama (2008) encapsulated the embodiment of the modern military service member when he stated "embody the spirit of service - a willingness to find meaning in something greater than themselves." With meticulous training, the military aims to produce tactical warriors and guardians of freedom, who are physically and mentally prepared for each situation that presents itself.

Veterans of Operation Enduring Freedom (OEF) and Operation Iraqi Freedom (OIF) have faced unparalleled challenges not experienced by service members of pre 9/11 warfare. The on-going efforts have resulted in a unprecedented number of deployments. A decade after the war began, more than 2.5 million service members had deployed to aid the efforts in either Iraq or Afghanistan, and 48\% of those had completed two or more tours of duty (DOD, 2010). Consequently, one in six combat veterans returns home with a severe injury, primarily as a result of exposure to an improvised explosive device 
(IED). Due to improved technology, transportation and medical advances, seven of eight wounded $\mathrm{OEF} / \mathrm{OIF}$ service members survive their injuries, a significantly higher ratio than ever reported in military conflicts in the past century (PEW, 2011; Weisskopf, 2007). The challenges returning from combat have been well documented, including; post-traumatic stress, depression, substance abuse and other mental health concerns (Toblin, Riviere, Thomas, Adler, Kok \& Hoge, 2011). In fact, the results of a recent study conducted by Pew Social Research (2011) found the majority of OEF/OIF veterans surveyed reported experiencing adversity adjusting to civilian life post-deployment, a figure doubled from previous military engagement. Wounded combat veterans in particular, have been confronted with a personal challenge of regaining a sense of self post-deployment after acquiring a career threatening injury (Carless, Peacock, McKenna \& Cooke, 2013; Perrier, Smith, Strachan \& Latimer-Cheung, 2014; Smith \&True, 2014). The opportunity to continue service exists within the military, even after a service member is deemed unfit due to a combat sustained injury by the Physical Evaluation Board. For example, the Army's Continuation On Active Duty status allows those who apply and qualify to remain in their Military Occupational Specialty (MOS) in accordance with each individual's limitations and still be eligible for promotion (Continuation On Active Duty, n.d.). Although this option provides service members with job security, many of those who thrive on the combat experience struggle with the fact they may never again be deployable (PEW, 2011; Smith \& True, 2014). In the past decade, the U.S. military has made a conscious effort to cultivate innovative programs for injured service members. 
The use of sport programs for rehabilitation and integration is not new phenomena, but more recent programming, and partnership initiatives have provided expanded opportunities for service members to re-establish themselves as elite athletes post injury. Physical activity and sport have successfully been used as forms of rehabilitation for injured veterans since World War II (Bates \& Anderson, 2011; Brittain \& Green, 2012; Chockalingam, Thomas \& Duval, 2012). In 1943, Dr. Ludwig Guttmann became the first doctor to formally prescribe sport for rehabilitation for military personnel, proposing that sport could act as a curative factor to regain strength and foster self-respect, while providing a means for social re-integration (Bates \& Anderson, 2011; Brittain \& Green, 2012; Carless, Peacock, McKenna, \& Cooke, 2013). The increase in the number of service members returning from combat with life-changing injuries over the past decade has driven the demand for therapeutic recreation and community-based adapted sport programs.

The U.S. Government has recognized the value and importance of such programs and responded with increased funding to aid adapted recreation and sport programs (Brittain \& Green, 2012). In 2004, the U.S. Paralympics, a division of the United States Olympic Committee, joined forces with the USAF to create the Paralympic Military Program (PMP). The PMP introduces service members with newly acquired disabilities to Para-sports through nationwide camps and clinics, with the aim for service members to channel their competitive spirit and discover the opportunities that exist in elite sport, with the potential to represent their country on a different battlefield (Bates \& Andrews, 2011). Individuals who demonstrate the commitment and skill to compete at the elite level are afforded the opportunity to join the World Class Athlete Program (WCAP). The 
program provides support and training required to be successful in national and international competition while maintaining their professional military career (WCAP, n.d.). Additionally, within certain branches of the U.S. military, specialty units exist with the intent to train service members to win competitions and enhance combat readiness, through clinics, while showcasing talent in an attempt to recruit new service members. As early as 2010, these units have expanded to include Paralympic sections. These sections are not considered part of the Wounded Warrior program, but rather highly competitive teams, in which only a few qualified individuals are selected to the unit through a screening and tryout period (US Paralympics, n.d.).

It is not surprising that the U.S. Paralympics and the U.S. military have united to rehabilitate veterans with acquired disabilities. Many sports, particularly those recognized as Olympic events evolved from centuries of tactical military training practices (Bates \& Andrews, 2011; Goodwin, 2008). The athleticism of combat service members parallels that of elite sportspeople. Both are dedicated to physical and mental training, have the desire to compete/win, thrive on adrenaline, yet maintain resilience under stressful conditions, all of which make service members ideal athletes (Goodwin, 2008). Elite combat units such as the U.S. Navy Seals and U.S. Army Special Operation Forces aim to prepare service members as tactical athletes through a comprehensive strength and physical fitness program designed to promote operational readiness (Stephenson, Dawes \& Snyder, 2014). With such preparation, combat service members are ideally suited to thrive in a competitive sport environment, enabling Paralympic sport to serve as a vehicle for those with disabilities to negotiate their post-war identity. 
In recent years, particular attention in adapted sport research has been directed towards the value of sport and physical activity on the well-being of veterans with acquired disabilities. New lines of research explore the influence of sport and physical activity on various aspects of psychological wellbeing and growth such as: (a) motivational processes, (b) sense of achievement, (c) post-traumatic growth, (d) resilience, (e) self-concept and (f) athletic identity. Researchers have made significant findings in terms of the psychological benefits of sport participation, yet only recently have studies recognized the value of identity formation post-traumatic injury, particularly for combat veterans.

Identities are considered social categories that develop through social interactions and lived experiences that individuals adopt as self-descriptive and self-defining (Thoits, 2011). Quintessentially, identities are answers to the question "Who am I?" and validate ones' purpose in life. According to Thoits (2013) “people typically occupy multiple roles at any one point in the life course (e.g. 'I'm a daughter, sister, aunt, journalist, and community volunteer)" (p. 374). The hierarchy or value of these identities are grouped and ranked based on importance (Thoits, 2013). In comparison to civilians, combat service members face phases of identity change over their career based on their unique experiences from basic training to deployment and beyond, a challenge which can be further be exacerbated upon acquiring a disability (Danish \& Bradley, 2013; Smith \& True, 2014). The recent work by Smith and True (2014) suggests that identity conflict, which can arise after separation from military combat service can be a potential trigger for mental health distress. This research contends that psychological conditions such as PTSD are almost exclusively diagnosed by formal institutions without fully considering 
the veteran's interpretation of their lived experiences which directly influence one's resilience, stability and ability to cope (Smith \& True, 2014). Participation in elite sport can promote the development of identity constructs similar to those derived throughout one's military career, creating a foundation to re-establish identity (Chockalingam, Thomas \& Duval, 2012).

The limited existing body of literature on the athletic identity of individuals with acquired disabilities primarily accounts for how athletic identity may be lost or reestablished post injury. For example, Crawford, Gayman and Tracey (2014) found that participation in adapted sports programs helped repair the identity of individuals who had acquired spinal cord injuries. The formation of identity was dependent upon each individual's involvement with sport prior to the injury. Moreover, Cocquyt and Sigmund (2011) determined that individuals who competed at an elite level showed significantly higher levels of self-perception than those who competed recreationally. The few studies involving veterans with acquired disabilities, explore the psychosocial benefits of participating in a singular sports camp, training clinic or adventure experience of short duration. The results of these primarily qualitative studies suggested that participation in sport facilitated positive changes related to their sense of self. Interestingly, the reestablishment of identity through sport did not necessarily transform into an athletic identity. Carless, Peacock, McKenna and Cooke (2013) found in terms of identity, participant's orientation tended to be in the present moment, which was favorably compared to the recent past, thus suggesting that the individuals made connections with valued constructs of a pre-existing sense of self as a military service member. To date, research efforts have not explored the impact training full-time in elite sport programs 
funded by the military may have on the re-establishment of identity of combat service members with acquired disabilities. Further, inquiry on veterans who choose to continue their service may have implications for need and development of future military sport programming.

The current body of knowledge on the influence of sport in the re-establishment of identity of combat veterans is sparse and superficial. Recent studies have implied that identity can have significant implications on the mental health of veterans postdeployment (Carless, Peacock, McKenna \& Cooke, 2013; Smith \& True, 2014). As of 2012, of the approximately 4100 service members who received a traumatic injury, such as major limb loss, severe burns and moderate to severe traumatic brain injury, only 167 service members returned to active duty status (RADS) (Koebler, 2012). For many of these veterans who will no longer be able to serve in the same capacity, the path to Paralympic sport may serve as a respected alternative to the battlefield. It is essential to gain further understanding of how elite sport programs influence the self-identity for those on RADS status, in a continued effort to provide meaningful alternatives for veterans with acquired disabilities within the military.

\section{Statement of the Problem}

Military veterans who sustain a traumatic injury in combat are far too often subjected to the realities of transitioning to civilian life well before their anticipated retirement. The majority struggle to regain a sense of identity post injury and very few are afforded the opportunity to continue their service in a personally meaningful capacity (Carless, Peacock, McKenna \& Cooke, 2013; Hawkins, Cory \& Crowe, 2011; Lundburg, Bennett \& Smith, 2011; Smith \& True, 2014). Even less is known about those who 
continue on active duty status. Overwhelming evidence suggests participation in sport and physical activity by veterans with acquired disabilities can have both physiological and psychological benefits (Day, 2013; Machinda, Irwin \& Feltz, 2013; Tedeschi \& McNally, 2011). Based on Smith and True (2014) findings, a majority of combat veterans experience some form of identity conflict upon separation from the military. The inability to re-establish a strong sense of self can become the catalyst for various mental health concerns. Unfortunately, few studies have examined the relationship between sport participation and the re-establishment of identity of combat veterans after acquiring a disability.

The purpose of this study is to explore the influences of participation in an elite military sport program has on the self-identity of active duty services members with acquired disabilities. The overall aim is to draw upon the life experiences of these service members who chose to continue to serve their country as a part of a specialized Paralympic military unit to gain an enhanced perspective on how elite sport programming influences self-identity post injury. With this understanding, recommendations can be made for further support, development, and implementation of in-service military elite sport programs.

\section{Research Question}

The proposed study plans to examine the following question:

1. What are the influences of an elite military sport program on self-identity of active duty service members with acquired disabilities?

\section{Definition of Terms}

For the purposes of this study, the following terms are defined as: 
U.S. Armed Forces (USAF)/ U.S. Military: The branches of the federal military, which consist of the Army, Marine Corps, Navy, Air Force and Coast Guard.

Service Member: An enlisted member of the military, although it should be acknowledged that services members may identify themselves as a Marine, Airman, etc.

Combat Veteran: A person who has served or is serving in the military post deployment.

Return to Active Duty Status (RADS): The opportunity for service members wounded in combat, who are declared medically unfit to continue their service in a similar capacity considering their physical limitations.

Identity: Social categories learned through social interactions and lived experiences that individuals adopt as self-descriptive and self-defining (Thoits, 2011).

Target Sport Unit: The elite miltary sport unit in focus for the study.

\section{Unique Need for Confidentiality}

Due to the unique nature of the population under investigation several safeguards were employed to protect the anonymity of the participants. Data was coded for participant confidentiality prior to analysis. Further, pseudonyms were assigned to both the military unit and participants within the unit, all potential identifiers (name, rank, military branch, injury, etc.) were removed and demographic details are presented in aggregate.

\section{Method}

\section{Research Design}

A qualitative research design using a phenomenological approach was used to gain understanding of the perceived influences on self-identity of RADS service 
members who participated in an elite military sport program. Phenomenology involves the study of a small number of participants who share a "lived experience" through extensive engagement to develop patterns, similarities and relationships of meaning (Cresswell, 2009). More specifically, the Husserlian approach aims to discover the raw experiences, as described by the research participants with minimal influence by the researcher (Moustakas, 1994). The descriptive orientation of Husserlian phenomenology is designed to capture the personal perceptions, memory, emotions and thoughts (Moustakas, 1994). For the current study, the value of this approach is the rich details of the individual stories told by each service member from enlistment to acquiring a physical impairment in combat to training for the Paralympic Games within a specialized military unit.

The study process was designed to be data driven and was not grounded in any pre-existing framework or used to validate specific theoretical models, therefore, allowing any unforeseen themes to transpire from the research questions. Upon conclusion of the data analysis, the researcher remained open to the possibility that larger constructs may have influenced the participants' experiences. Although the body of knowledge which recognizes the benefits of sport and physical activity on veterans with acquired disabilities, there is a paucity of research surrounding combat wounded veterans who return to active duty post injury, thus employing a specific theory may limit the scope of the lived experiences told by the service members.

\section{Sampling}

Study participants were recruited from a unique unit within a branch of the U.S. Armed Forces. For the purposes of this study, the unit will be referred to as the Target 
Sports Unit (TSU). The TSU was formed with the intent to train service members to win national, international competitions and enhance combat readiness through clinics, while showcasing the marksmanship talent of the military in an effort to attract new service members. In 2010, a Paralympic section was added to TSU in a continued effort to demonstrate the talents of the diverse group of service members who represent the modern day military. This section is not considered a Wounded Warrior program, but rather a highly competitive team within the TSU, in which only a few qualified individuals with acquired combat injuries are selected through a rigorous tryout period (U.S. Paralympics, n.d.). At the time of data collection, five service members were assigned to the Paralympic section of TSU.

Extreme case, purposive sampling methods were used due to the unique nature of the population under investigation. Extreme case sampling, which is defined as "the process of selecting highly unusual cases of the phenomenon of interest or cases that are considered outliers, or those cases that, on the surface, appear to be the 'exception to the rule' that is emerging from the analysis" (Cohen \& Crabtree, 2008). For the study, extreme case was the most appropriate form of purposive sampling, based upon the specific criteria required to hold their current assignment within the military, as well as similar life experiences shared.

Access. The primary researcher had an established relationship with the population of interest through previous employment with the sport's National Governing Body. After receiving approval from the university's Institutional Review Board (IRB), the unit's Non-Commissioned Officer in Charge (NCOIC) was asked by the primary research to forward a recruitment e-mail and letter to the five potential participants. The 
e-mail introduced the researcher, as well as described (a) the purpose of the study, (b) a description of the data collection procedures, (c) statements explaining voluntary participation, confidentiality, anonymity and the right to opt-out of the study at any point. Those contacted were asked to respond by e-mail or phone if they interested in participating. An official consent form was completed from each participant prior to the commencement of the first interview.

\section{Participants}

Participants $(n=4)$ were male and ranged in ages from 21 to 39 years $(M=32)$. Each participant joined the military following high school with the primary objective of serving on the frontline. In addition to the descriptions below, Table 1 provides a general timeline of each participant's service in the military both pre and post injury.

Military entry. The participants began their initiation into the military with ten weeks of intensive basic training, before being assigned their MOS. The standardized military aptitude test taken upon enlistment opened the doors to various occupations within the military, but the participants remained steadfast to their goals of combat-ready positions. The participants indicated that joining the military was in response to a perception that their country needed them and that being a service member was something they had waited for their entire lives. Two participants had served in the military prior to OIF/OEF and were involved with various peacekeeping efforts. After the events of $9 / 11$ the participants engaged in preparations for deployment, which ranged from 10 to 24 months. The group of study participants had $1-7$ years $(\mathrm{M}=3.25, \mathrm{SD}=$ 2.06) of military experience prior to receiving OIF/OEF deployment orders. 
Deployment sustained injury. Three of four participants indicated they sustained their injury within the first three months of their OIF/OEF deployment $(\mathrm{M}=$ 4.5, $\mathrm{SD}=3$ ). Although no deployment experience is the same, Osran, Smee, Sreenivasan and Weinberger (2010) describe modern day warfare as an 'asymmetrical' battlefield bombarding service members with copious amounts of hidden explosives, while military safe zones are barraged with rocket propelled grenades and mortars. Of the OEF and OIF service members wounded in action, $65 \%$ of injuries are caused by blasts and fragments from improvised explosive devices, rocket propelled grenades and other explosive devices (Bascetta, 2007). Typical injuries sustained in modern day warfare include burns, limb loss, traumatic brain injury and post-traumatic stress disorder. Study participants sustained similar injuries that resulted in permanent physical and psychological implications, which required a need for extensive recovery and rehabilitation periods. The rehabilitation process for the study participants ranged between $1-2$ years $(\mathrm{M}=1.5, \mathrm{SD}=0.57)$.

Unit entry. Upon rehabilitation, study participants were recruited to tryout for the TSU. These individuals were eligible to tryout as they met the following criteria required by TSU: (a) OIF and OEF veteran status with a background in Combat Arms Military Occupation Specialties (MOS), (b) current active duty classification, (c) Purple Heart recipient, (d) meeting the International Paralympic Committee eligibility classification and (e) expert marksmanship skill, concentration, self-motivation and dedication to the unit's mission (US. Paralympics, n.d.).

Unit membership. Individuals who are assigned to TSU divide their time between practicing their marksmanship skills on the range in preparation for competition, 
competing for the United States at national and international events, as well as hosting clinics for other units within the military branch. The time spent at the TSU varied between 1-10 years $(\mathrm{M}=4, \mathrm{SD}=4)$.

\section{Data Collection}

Data were collected in the form of in-person, semi-structured interviews, which were audio recorded. In addition, the primary researcher took field notes. Although broad, open-ended questions are often best suited for phenomenological exploration, research suggests this is not the most appropriate approach when interviewing individuals who may have post traumatic stress disorder (PTSD) or a Traumatic Brain Injury (TBI) (Paterson \& Scott-Findlay, 2002). Therefore as a precaution, semi-structured interview guides, along with probes for each interview phase were used to facilitate data collection. A clinical psychologist with expertise in PTSD reviewed all interview scripts and correspondence materials prior to the start of the study.

The interview process took place in three phases, with each interview approximately 20 minutes in length, one each day, over a period of three consecutive days. Individuals who have experienced a TBI or PTSD can become easily fatigued with the intensity of an extensive interview process. Responses can become less focused and more succinct in the later portions of an in-depth interview (Paterson \& Scott-Findlay, 2002). Therefore, conducting brief interviews, over a three-day span was employed as an attempt to capture the full attention of the participants in short intervals (Rolls, Inglis \& Kristy, 1997), while inducing the least amount of stress. This technique is also recommended when investigating a unique phenomenon experienced among a small group of individuals (Seidman, 1998). The initial interview encompassed the 
participant's past experiences related to becoming a service member. The second interview discussed the current experiences related to training for the Paralympics, as a member of the specialized instructor marksmanship unit. The third interview connected the two points in time, attempting to bring to light the transformative experiences through life contexts.

Pilot. A pilot study was conducted for the researcher to become acquainted with interviewing veterans with acquired disabilities and to pilot the proposed interview questions. Upon completion, the researcher along with a colleague with expertise in qualitative interviewing evaluated the audio-recordings to ensure the intended interview questions and probes were phrased in a way, which did not hinder or influence the participants' responses.

Setting of interviews. Scheduled interviews with participants took place in a private office at the specific unit's training facility. This location was in close proximity to the practice facility and provided a convenient, private and familiar location for participants. An environment free of distractions and familiar to the participant was selected to help reduce any unwarranted stress or anxiety for individuals who might have experienced PTSD or a TBI (Hibbard, Uysal, Sliwinski \& Gordon, 1998; Paterson \& Scott-Findlay, 2002). In addition, all efforts were made to accommodate participants' training schedules and requests for specific interview times. The researcher was cognizant of the potential fatigue surrounding training schedules, and arranged interviews on an individual basis when participants felt they would be most calm and alert (Paterson \& Scott-Findlay, 2002). 
Additional precautions. As final precautionary measures due to the sensitive nature of the interview topics, arrangements were made to have military medical staff onsite throughout the interview stages in the event the questions triggered a PTSD episode. Participants were also offered Veteran's Crisis cards with contact information for the website and the telephone hotline, as well as a counseling referral list for local and national services. The crisis counseling services provided veterans and their families with an outlet to receive confidential support if for any reason the topics discussed during the interviews triggered post-traumatic stress disorder symptoms or concerns. This information was shared with the participants prior to each interview.

\section{Data Analysis}

Data voice recordings from each interview were transcribed by a professional verbatim and saved to an individual file. All data were kept secure and confidential on an encrypted flash drive. Prior to analysis, individual interview segments were coded (e.g. P1_I1, P1_I2 and P1_I3) and all scripts were stripped of identifying information to ensure confidentiality.

Data were analyzed using an inductive phenomenological approach, which allowed patterns and themes to emerge within each transcript in an effort to describe, rather than explicate the lived experiences of the participants (Patton, 2002). The perspective of the researcher is one without bias and prejudices of the subject of investigation in an effort to best capture the participants' voices and experiences (Creswell, 2009). As recommended by Chan, Fung and Chien (2013), a reflective journal was kept by the researcher throughout the inquiry and data analysis process to maintain 
awareness of personal preconceptions. In addition, a personal statement of biases was created by the researcher and used for personal reflection throughout the study.

Each individual transcript series (all three interview components for each participant) was meticulously read and re-read in an effort to fully understand the context and meaning of the statements. After obtaining a sense of the material as a whole, the researcher and two experienced reviewers independently coded all four transcripts from interview one. A meeting between the researcher and the reviewers was held to review the transcripts, establish intercoder agreement, revise operational definitions and discuss any discrepancies. As a reliability check, one third of the data was covered with an agreement of at least $80 \%$, as recommended by Neuendorf (2002). Once agreement had been reached, the process was repeated for interview two and three. To ensure coding consistency, the researcher and reviewers met upon the completion of coding all transcripts to verify the coded themes and subthemes. Variances in coding were discussed until consensus was established. Direct quotes representative of the emergent themes were organized into a excel spreadsheet codebook. The researcher then was able to attached significance to the emergent themes and make appropriate connections of the interpreted meanings to previous literature and existing theories.

Member checks. Study participants received an e-mailed copy of their transcript and were asked to review the document for accuracy and completeness. Participants returned the transcripts with minimal modifications to their statements.

\section{Results}

The purpose of this study was to explore the influences of participation in an elite military sport program on the self-identity of active duty service members with acquired 
disabilities. As a result of the inductive data analysis, several overarching themes and sub-themes transpired. A response pattern characterized by the key themes of (a) goal orientation, (b) champions through transition, and (c) the unit were identified and illustrated through the voices of the participants to convey their lived experiences throughout their military career as it related to their perceived self-identity post acquired physical disability.

\section{Theme I: Goal Orientation}

Across the life stories told by the participants, goal orientation became a common thread throughout their military careers. Goal orientation emerged in three distinct time periods during their military journey. These are represented through following subthemes (a) desire to serve on the frontline, (b) determination to return and (c) a new mission.

Desire to serve on the frontline. Early in the interview process participants indicated a strong desire to enlist immediately out of high school or as soon as they were legally eligible. When asked to reflect upon their initial enlistment, the participants described a strong desire to serve their country, which materialized early in youth. Participants discussed a family history of service, which for many was in part inspiration to continue the family legacy. This is represented in the words of William:

I knew when I was a kid that's what I wanted to do when I grew up. Pretty much all my uncles, both sides of the family, and grandfather and everything, they all have served. Ever since I was a kid that's all I ever wanted to do. [...] I watched pretty much every war movie you could ever think of. I just thought being a 
service member, and still think that being a service member is one of the greatest things you can do for your country.

The men not only had a strong interest in pursing a military career, but each specifically indicated specific aspirations to serve on the frontline in a tactical position. Although each tested high enough on the Armed Service Vocational Aptitude Battery (ASVAB) to qualify for specialty occupations, participants chose combat positions. As Cameron shared, "I took the ASVAB test and I had a high enough score that I could do whatever job I wanted, but I specifically picked that job." The majority of participants indicated that frontline combat positions were appealing because they provided an opportunity to deploy and see action first hand. The following quotes are representative of this:

"All that was on my mind, was getting that deployment, seeing that combat, and doing that thing that everyone wanted to do." (Cameron)

"I wanted to shoot guns and blow up stuff." (Gabriel)

"When I joined, I really wanted to see action." (Juan)

Determined to return. Participants described how their deployment ended unexpectedly due to an injury acquired in combat as a result of an explosive device. All but one participant received their injury within the first three months of their first deployment experience. Although their injuries varied in severity, each expressed a strong will to return to active duty status. Gabriel described his initial response after learning there was an option for wounded service members to stay in the military:

Once I heard that I could stay in, it was already determined - that's what I was going to do, that's what I wanted even before I didn't know that I could do that, or 
actually do that, but once I got the information that it's possible, it was like done deal.

Even after receiving a fairly negative prognosis of the severity of his injuries, Cameron was determined not to allow his injuries to define him or limit his ability to continue his service to his country. He shared:

I'm the most seriously injured person here [Wounded Transition Unit]. I've been through more than anyone else has been through, all these 200 people that are here. I'm going to be one of the people that gets out of here, and gets back to the regular military. I'm going to do that. That was my plan, to get back, and show the people that even if you're really damn injured, you can still do what you want to do, if you want it.

Although each participant experienced a different journey to recovery, all expressed an unwavering commitment to their goal, setting forth grueling conditioning regiments in order to return to peak physical form and taking every possible measure to ensure they would be successful. The following quote from Gabriel illustrates this determination: I didn't know how strict they were on making that decision whether your RADS was approved or not, so I busted my ass. I got to walking and running again. That's when I decided I needed to get back in shape, so I started doing road marches, running, just getting back into shape, and everything that I did I always had some kind of senior NCO there to document it and be a witness of it, so I had all the stuff documented. "Hey, this guy can still road march. He can still carry his own weight," stuff like that and I ended up maxing the PT test as an amputee. 
Rather than allowing self-doubt to manifest after a traumatic injury, the descriptions provided by the participants suggest sustaining an injury became a catalyst to preserve. Each recognized the journey would not be easy, but their self-determination was evident through their continued actions.

New mission. Unlike other RADS assignments, participants took part in a rigorous tryout process for TSU, which challenged the men physically and mentally, as well as assessed their ability to perform specialized marksmanship skills. The Target Sports Unit's mission was different than other military units, yet the expectations to perform were still very high. The opportunity to deploy was not apart of the mission for this unit, but instead the participants trained full-time for the opportunity to represent the United States and the military at the Paralympic Games, as well as serve as unit instructors. It offered new challenges and diverted attention towards new ambitions to represent their country in a different uniform. Athletic goals were described as a focal point of the participants' short-term goals in the scope of their military objectives. The following statements are representative of their athletic goals:

"So while I was competing, I wanted to be the first active duty service member to make a Paralympic team." (William)

"I've got a real mission in my head that I want to achieve. I've got a big goal that is going to take a lot of my energy." (Cameron)

"In five years, I want to be as good as the world ranked athletes." (Juan) Interestingly, Juan and Gabriel indicated that although their short-term goals were athletically related based on their current military assignment, their desires extended to bigger military ambitions. Gabriel shared: "I set a goal that I wanted to do twenty years 
and retire as a Sergeant Major. I'm still going to work towards that goal." Similarly, Juan saw the unit as a stepping stone to greater opportunities, as he stated: "My plan was only to be here six years because there are other things I want to do, other dreams I want to obtain [...] pursuing my original goal to be a part of the special operations one day."

\section{Theme II: Champions Through Transition}

During the interview process, participants were asked to reflect upon their support system throughout their military career. It became evident that each participant established a strong support network, which transitioned during various stages of their career. The following three sub-themes represent the various champions of support that were consistent across all life stories: (a) family, (b) military support and (c) teammates.

Family. The participants spoke regularly of encouragement and support of family members throughout their interviews. From enlistment through to the present day, spouses and family were specifically mentioned as the core foundation of support for these men. When Gabriel decided to return to the military after a nine-year hiatus, he stated: "my wife supported me 100\%." William described a support network that had been there through it all: "My family is my biggest supporter. They have seen me at my best and my worst... They have helped me through the whole process of recovery and now in competition." The importance of family was represented most frequently during the recovery period post-combat injury. During a time of uncertainty, family members played an important role in fostering positive and supportive environments necessary for the participants to recuperate back to health, as Cameron mentioned: "At my weakest moment, when I was most vulnerable, she [wife] helped me out. That was one of my steps towards success, having a successful life after the injury, was that support there." 
In their current positions within the military, in a unit that primarily focuses on competition medals and serving their country on a different stage, the participants reiterated the continued support from family members as described below:

"My dad is proud of me and what I do." (Juan)

"Still to this day, my parents couldn't be more proud of me." (William)

Military support. For the participants, the military was described an extension of their family and an equally influential foundation of support throughout their military careers. The camaraderie with fellow service members was commonly spoken about leading up to and during deployment. When reflecting upon fellow service members, the participants' discussions tended to focus on trust, teamwork and reliance on others for survival. As shared by Juan: "To me, they were the best, because you built that bond. [...] I trusted them with my life, and I hope they trusted me with their lives one hundred percent." Cameron's reflection represented similar thoughts: "By the time we deployed we were pretty well-oiled together. [...] Ours was one of the lower battalions during that time for injury rates. I think that was because we were training so long before we went there."

During the rehabilitation process Gabriel, Juan and William indicated new forms military support from higher-ranking officials. These individuals were described as people who encouraged recovery and provided physical, mental and emotional support for the men on their desire to continue their military journey. Upon reflection, Gabriel recalled; "The commander would call me once a week, just to see how I was doing." Juan's desire to return to active duty was supported by his platoon Sargent who devoted 
his time and effort to intensive training over a four-month period to transform Juan back to combat ready shape. Juan described what his mentor meant to him:

He was my mentor, my teacher, my friend, and boss at the same time. [...] He was there by my side, watching me, making sure I was fine and kind of guiding me along the way. [...] Him being there for me is a big factor for my recovery and to going back to active duty. I am very thankful that he was there, because honestly, I don't think I could have been able to go that far without him.

For Cameron, the support from superiors came from a lack of special treatment upon his return to service. As he described: "It was like "okay if you're going to be here, you're going to do what everybody else has to do. Sorry. " I think I needed that."

Teammates. When asked to describe their support system in their current position, each participant described their primary support to be their teammates. Within TSU, the participants practice with other active duty service members without disabilities who train for the Olympics in their respective disciplines. Juan described the mentorship of the more experienced members of the unit as a form of support: "They take all that good vibe and they pass it on to someone else, especially some of the younger guys." Additionally, although family was mentioned as a form of support throughout all phases of the participants' careers, the shared mission of team members from the unit offered a different form of support. This illustrated by a comment by Cameron:

My wife really wants me to do well because she's my wife and she loves me. She doesn't really understand. I don't think she understands the significance of it. It's not that she just doesn't care. It's just that she doesn't know, because she's not 
here. The unit, the guys here in the office, the Olympians, the past Olympians, the Paralympians, they know how much work it takes.

\section{Theme III: The Unit}

A theme category that transpired from the data revolved around the characteristics of TSU. Although each participant admitted to not having any knowledge of TSU originally, when the opportunity to tryout was presented, each decided to it was worth a try. The influential characteristics of TSU as described by the participants were organized into the following four sub-themes: (a) new challenges, (b) pride, (c) environment for success and (d) transferrable skills.

New challenges. The Target Sports Unit provided the participants with a new focus, and with that came a skill set that required mastery. While physical fitness and athleticism reflect key components of successful military training regimen, the participants described being challenged in new ways. Cameron shared: "I've played all kinds of sports, and I've been good at all kinds of sports, but this is the most challenging thing anyone can ever do, mentally." Gabriel compared it to his former training in the military:

It's a different kind of feeling. [During military training] You go out there and get pumped up and aggressive and you can use your adrenaline to your favor. [...] Here it's the complete opposite. You have to figure out how to keep your adrenaline at bay and control your nerves and your emotions and stuff like that. [...] I am still trying to figure out the mental part of this sport. Similarly, Juan described the challenge of mastering the skill requirements of TSU: "There is so much more to this than what I had realized. Everyday I'm learning 
something different about this sport." It was evident that the new unit poised challenges that were of surprise to the participants, but these were all described as welcome challenges that provided a source of motivation. As Cameron shared: "You put so much effort into it, and you don't get the result you want. Sometimes you don't know why, and it's frustrating. It drives you to do better."

Pride. When participants began to describe their current situation at TSU, a strong sense of pride was associated with their statements. Although time spent at the unit varied from six months to nine years, each participant spoke of the unit in high regards. As captured in a statement by Juan: "To me, being here is definitely an honor and a privilege to be training amongst the best." Cameron described how he feels when he has the opportunity to compete internationally: "When I go overseas, I'm representing not only my country and not only the military, but this unit. I'm really proud that I'm in this unit." For William, pride for TSU and what it means to him came from a different place, as he shared: "I've had friends that had given their lives in combat, so I compete for them." The Target Sports Unit provided him with the opportunity to do something meaningful for his fallen comrades.

Atmosphere for success: Positive, competitive and inclusive. The participants described TSU as a different atmosphere in contrast from where they came from. There was a strong indication that unlike other military units, the mission of TSU required a different mentality. Gabriel elaborated on this sentiment by sharing: "Coming from a big military unit, it doesn't feel like a unit. It's very individualized here. It's based on individual accomplishments, versus team or unit accomplishments." William simply 
described TSU as “a team of individuals. ” Juan further expands on this concept, but brings to light the emphasis of the team aspect, as described in the following statement: It's an individual thing because everyone here that comes to shoot, they are trying to beat the guy next to them, to the left and right. [...] But as a team, we can teach each other how to be better.

Even though the transition was described as a change from what the participants were used to, the men portrayed TSU to be a competitive, positive and inclusive environment. Cameron shared: "The best people come here to shoot and the people that want to be the best." Cameron recognized the importance of competition for success, as he stated: "They're just so damn good that if you shoot with them you're going to get better." Juan being one of the least experienced team members was specifically grateful for the positivity the emanated throughout TSU. He described the unit as: "It's very positive here. It's almost like a sickness here, almost. [...] Everyone is positive and everyone thrives on trying to be the best, it just disseminates amongst everyone."

One of the strongest veins of support and motivation for the participants' came from what was described as an inclusive environment. Although the men were assigned to the Paralympic section of the unit, they trained side by side with service members without disabilities, including several distinguished Olympians. The Target Sports Unit prides itself on a history of internationally acclaimed marksmen and Olympic champions. As shared by Cameron: "I'm laying on the ground like everybody else, so it doesn't affect the way I shoot. I am shooting up here beside one of the best pro shooters on the planet earth." Likewise, Juan highlighted the similarities between the open shooters and the 
Para-shooters: "We still shoot the sport, we shoot the same guns, the same gear, the same equipment, it's just different events."

Transferrable skills. The sport of shooting was naturally relatable for the participants, as each had years of experience around military artillery prior to joining TSU. Interestingly, the participants indicated that once they began at TSU, they were surprised at how little they actually knew about marksmanship. In addition, the important of mastering this skill set appeared to be valued, especially by the individuals who had aspirations to return to a combat unit. Gabriel shared:

Once I started getting into Olympic shooting, it makes me want to go back to shooting an M4 again and implement all the stuff I've learned. Because I found out when I got here that I only knew the basics. Because with competitive shooting, there is so much involved and so much you have to pay attention to that I never did as just a regular service member shooting at silhouette targets.

Similarly, Juan who expressed interest in one day attending special operations schools frequently discussed the transferrable skills he was learning at the unit. He described how valuable his current training would be for his future aspirations. This is illustrated in the following quote:

...these schools are trying to break your mind down. Can you still operate when all these factors come at you? Can you still function well with all this stuff that's just bombarding your mind and your body? It's kind of the same thing here, when you're shooting in these finals, shooting in these big international events, and the Olympics. It's pretty much the same thing. If you can do that on a daily basis, 
you're already beat half of these schools by $80 \%$. The other $20 \%$ maybe comes down to can you perform well. That's pretty much it. (Juan)

Moreover, several participants shared statements that highlighted the binding attributes between the two military assignments. Even though the duties appear to be very different on the surface, tenets central to both roles were evident, as shared by William "Service members and athletes share the same core values, the desire to be the best and proficient at their jobs." (William). Similarly, Gabriel stated: "Well as a service member, a combat service member, you are naturally competitive because your job is to win."

\section{Discussion}

The findings of this study provide a unique perspective on the perceived influences of an elite military sport program on the self-identity of active duty service members with acquired disabilities. Whereas previous studies concentrated on short-term sport experiences such as camps or outdoor expeditions (Burke \& Utley, 2013; Hawkins, Cory \& Crowe, 2011), the current study explores the experiences of those who chose to continue on active duty, serving their country by training full time for the Paralympics within the context of an elite military sport program, specifically the TSU. Furthermore, the present study builds upon the existing body of literature on the rehabilitation benefits of sport and physical activity addressing the need for research of long-term recovery programming. Richmond, Thompson, Deatrick and Kauder (2000) advocate that recuperation from a physical injury is an active process and continuous journey of personal growth that requires both internal and external resources. The present study 
supports this notion, by examining the role of sport as an active agent in the (re)establishment of identity post combat injury.

From the inductive analysis, three emergent themes were identified: (a) goal orientation, (b) champions through transition, and (c) the unit. Interestingly, concepts of self-determination theory (SDT) were present across the narratives of the participants' described military careers. Self-determination theory has frequently been used within therapeutic recreation and sport for veterans' literature, but additionally offers implications regarding identity construction. Therefore, this discussion has been framed using the constructs of SDT to provide insight into the key factors identified that may have influenced the perceived identity of active duty service members with acquired disabilities who participate in an elite military sport program.

Human motivation is the primary focus of SDT, which suggests that manifestation of self-determination is most apparent in individuals who experience a sense of autonomy, competence and relatedness (Ryan \& Deci, 2000). Together these essential components foster personal growth and wellbeing. Furthermore, SDT aids in our understanding of the processes of which identities are acquired. Through the lens of SDT, the internalization and regulation of an identity can vary based upon an individual's intrinsic and/or extrinsic motivation. More specifically, when personal value is attached to an endeavor, there is a higher tendency for internalization of that role, as well as persistent engagement in the activity, which in turn increases the saliency of that identity (Ryan \& Deci, 2012). Within the context of sport, SDT conveys that activities that satisfy an individual's psychological needs prove to be more meaningful (Deci \& Ryan, 1985). The following discussion takes a chronological perspective of the military careers 
of the participants, outlining the various components of STD that appeared to be woven throughout their journeys.

\section{Fostering Self-Determination}

From the findings, participants shared a common desire from an early age to pursue a career in the military and more specifically with a goal to acquire a combat position. Family and patriotism were identified as influences to pursue a military career. Furthermore, each described a strong desire to serve on the frontline in a combat position, which appeared to be fostered primarily though intrinsic motivation. After testing well above average on the ASVAB, participants happily turned down the more lustrous opportunities within the military for the high-risk combat positions. These findings align with Deci and Ryan (1985) who suggest that choice and opportunities for self-direction allow people to feel a strong sense of autonomy, an underpinning of self-determination. Additionally, the military infrastructure provided an environment rich in supports to promote both a sense of relatedness and competence. Intensive training within small units over several months prior to deployment helped cultivated competence, directed competitive tendencies and fostered a sense of camaraderie. Upon reflection, the bond between service members appeared to be of strong significance amongst the participants. Similarly to the findings of Mitchell, Gallaway and Millikan (2013) the importance of the relationships transformed during deployment from simply camaraderie to a brotherhood, one that is relied upon for safety and survival. This sense of relatedness was described as one only those who have shared in the experience, can relate to.

From Adversity Comes Strength 
When faced with adversity as a result of combat injury, the participants refused to acknowledge any physical or psychological limitations as they adjusted to life without a limb. The majority of the participants described the traumatic experience a catalyst towards a new positive outlook on life. Life post injury was to be lived to the fullest, in memory of those who did not return home and knowing their outcome could have been fatal. Berntsen and Rubin (2006) describe this phenomenon as event centrality, in which an individual attaches personal meaning of a negative event in relation to individual identity. These findings are further supported by Bernard, Whittles, Kertz and Burke (2014), who found when individuals perceive a traumatic event as positive and incorporate that experience into his or her identity, there is potential for increased personal growth, improved meaning of life and more satisfying personal relationships.

Within the resilience and post-traumatic growth literature, positive outcomes following a traumatic event have been associated with strong social support systems (Crawford \& Gayman \& Tracey, 2014; Day, 2013; Machina, Irwin \& Feltz, 2013). The findings from this study provide further evidence to support this. In their reflective accounts, the service members identified various levels of support during their recovery stages. Family members were described as the emotional support and physical caretakers the service members required to get back on their feet. However, it was the encouragement, guidance and the sponsorship of military superiors that became the crutches each service member needed to return to active duty. Overall, the robust social supports of the participants proved to be instrumental during their recovery and transition periods.

\section{Reconnecting Through Sport}


Although competition shooting required a completely different skill set than what the service members had previously been exposed to, it provided a connection to past interests and was closely identified with a fundamental component of their previous occupational responsibilities. Moreover, the responsibilities, expectations and competition of the TSU provided various challenges that met the needs of these goaloriented service members. The participants' described aspirations to master their marksmanship skills corresponds with the work of Ryan, Williams, Patrick and Deci (2009) who imply challenge, interest and enjoyment to be the primary motives of intrinsically motivated participation in activities such as sport. The intrinsic conquest for competence was further illuminated through both short and long-term athletic goals, which were described across all of the participants' narratives. Additionally, for two participants the discovery of a new skill set helped to reconnect with pre-injury military aspirations. These findings are comparable the work of Carless, et al. (2013) who found that participation in an physical activities with military undertones helped veterans with acquired physical disabilities rediscover a sense of purpose and connection to others. In addition the results support the efforts of Hawkins and colleagues (2011) who found that the exposure to competition through sport rekindled pre-injury interests and selfdetermination of veterans with acquired disabilities.

Unique to the current study, it should also be mentioned that training daily within an inclusive environment, surrounded both Olympic and Paralympic athletes provided the participants with an external source of support and motivation. Although the dynamic at TSU was described as "team of individuals" a stark contrast from that experienced on the battlefield, the service members embodied pride in the shared mission. Success within 
the new mission would require autonomy and cohesion of the mind and body from practice to the winning shot in the Paralympic Games.

\section{Programmatic Implications}

Contradictory to findings by Chockalingam, et al. (2012), who indicate that veterans are often referred to adapted sport programs after clinical recovery, the majority of the study participants were identified as potential candidates for TSU during the rehabilitation or transition process. Although none of the participants were familiar with the TSU prior to their invitation, each expressed a strong interest after learning about the sport-based program once introduced. Thus suggesting that the value of sport along the recovery trajectory continues to evolve with the collaboration of support specialists who are knowledgeable of the patient, their injury, aspirations and athletic interests, as well as the opportunities. Furthermore, programmatic offerings should consider sports that align with military practices such as hand-to-hand combat (boxing, judo), tactical (marksmanship, archery) and team oriented sports. The introduction of such programs to service members early in their recovery can provide the opportunity to continue to serve on active duty. Thus, continuing to foster the identity traits possessed by the participants prior to sustaining their combat injuries.

\section{Limitations}

The current study did pose a series of limitations that should be addressed. First, the study was limited to a small population of active duty service members who were assigned to a specialized marksmanship unit and consequently the results cannot be generalized across all service members recovering from a combat injury. Additionally, the population examined included only male service members. Although women are 
considered a minority group within this population, female service members are increasingly engaged in combat positions and are equally susceptible to injuries as a result of their service (PEW, 2011). Gaining insight of the experiences of female service members could provide an enhanced perspective of the phenomena of interest.

Furthermore, it should be mentioned that prior to data collection, the unit in focus experienced unforeseen restructuring, which displaced several service members and impeded recruitment efforts. The phenomenological approach taken for this study placed the researcher as the primary instrument for data collection. Although a conscious effort was taken to ensure objectivity, the researcher's previous experiences, knowledge and biases may have influenced the way the data was viewed and interpreted. Finally, the literature suggests that service members who are exposed to combat situations have difficulty reintegrating back to their domestic life stateside, in part because civilians cannot possibly comprehend what they have endured (Danish \& Antonides, 2013). While the researcher attempted to establish the trust of the participants, her lack of military experience may have potentially influenced the collection and interpretation of data.

\section{Conclusion and Future Research}

Ryan and Deci (2012) acknowledge that identities are negotiated and regulated over time through interactions within social contexts. Through the lens of SDT, the findings from this study depict a group of highly self-determined service members, who throughout the course of their military journey experienced a strong sense of competence, relatedness and autonomy. These constructs may provide insight into the motivational traits of a very small population of service members who return to the military following 
a war related injury. Furthermore, the within the context of an elite military sport program, the findings identify unique variables of the unit that provide meaningful experiences to meet the psychological needs of this specific population. Therefore, TSU became a bridge to mend and enhance the participants' internalization of the service member role and additionally served platform for personal growth. While participants' may have attached different meaning to this identity, such as new athletic responsibilities and challenges, the importance of continuing to serve within in the military remained central.

The current study was conducted using a three-phase interview approach, which relied on the personal reflections of the individual. Although, this technique gathered insightful data on the phenomenon under investigation, future research should attempt more longitudinal interviewing from initiation into the program, and a follow-up upon exiting the program. Additionally, future studies should attempt to explore military sport programs that include both men and women to compare and contrast experiences and motivational influences between the two groups. Finally, the current study touched upon the implications of participation in an inclusive environment. Further inquiry of inclusive programs for veterans and active duty service members with acquired disabilities and should be conducted to gain further insight into the benefits of such programs. 


\section{References}

Batts, C., \& Andrews, D. L. (2011). 'Tactical athletes': The United States Paralympic Military Program and the mobilization of the disabled service member/athlete. Sport in Society, 14(5), 553-568.

Bernard, J. D., Whittles, R. L., Kertz, S. J., \& Burke, P. A. (2014). Trauma and event centrality: Valence and incorporation into identity influence well-being more than exposure.

Berntsen, D., \& Rubin, D. (2006). The centrality of event scale: A measure of integrating a trauma into one's identity and its relation to post-traumatic stress disorder symptoms. Behaviour Research And Therapy, 44(2), 219-231.

Brittain, I., \& Green, S. (2012). Disability sport is going back to its roots: Rehabilitation of military personnel receiving sudden traumatic disabilities in the twenty-first century. Qualitative Research In Sport, Exercise \& Health, 4(2), 244-264.

Burke, S. M., \& Utley, A. A. (2013). Climbing towards recovery: Investigating physically injured combat veterans' psychosocial response to scaling Mt. Kilimanjaro. Disability \& Rehabilitation, 35(9), 732-739. doi: $10.3109 / 09638288.2012 .707743$

Carless, D., Peacock, S., McKenna, J., \& Cooke, C. (2013). Psychosocial outcomes of an inclusive adapted sport and adventurous training course for military personnel. Disability And Rehabilitation: An International, Multidisciplinary Journal, 35(24), 2081-2088. doi:10.3109/09638288.2013.802376

Chockalingam, N., Thomas, N., \& Duval, L. (2012). Should preparation for elite sporting participation be included in the rehabilitation process of war-injured veterans? 
Prosthetics And Orthotics International, 36(3), 270-277.

doi: $10.1177 / 0309364612447096$

Cocquyt, M., \& Sigmund, E. (2011). The impact of competition in physical activity and sport on the self-perception of individuals with physical disabilities. Acta Universitatis Palackianae Olomucensis. Gymnica, 41(1), 43-50.

Cohen, D. J., \& Crabtree, B. F. (2008). Evaluative criteria for qualitative research in health care: Controversies and recommendations. The Annals of Family Medicine, 6(4), 331-339.

Continuation on Active Duty. (n.d.). Retrieved from http://www.armyg1.army.mil/docs/COAR_RADS_Brief_(9\%20APR\%2009).pdf

Crawford, J. J., Gayman, A. M., \& Tracey, J. (2014). An examination of post-traumatic growth in Canadian and American ParaSport athletes with acquired spinal cord injury. Psychology of Sport and Exercise, 15(4), 399-406.

doi:10.1016/j.psychsport.2014.03.008

Creswell, J. W. (2009). Research design: Qualitative, quantitative, and mixed methods approaches. Thousand Oaks, CA: Sage Publications.

Danish, S. J., \& Antonides, B. J. (2013). The challenges of reintegration for service members and their families. American Journal Of Orthopsychiatry, 83(4), 550558. doi:10.1111/ajop.12054

Day, M. (2013). The role of initial physical activity experiences in promoting posttraumatic growth in Paralympic athletes with an acquired disability. Disability And Rehabilitation: An International, Multidisciplinary Journal, 35(24), 20642072. doi:10.3109/09638288.2013.805822 
Defense Manforce Data Center. (2015). Retrieved from

https://www.dmdc.osd.mil/appj/dwp/dwp_reports.jsp

Department of Defense. (2010). Report on the Impact of Deployment of Members of the Armed Forces on Their Dependent Children. Retrieved from http://www.militaryonesource.mil/12038/MOS/Reports/Report-to-Congress-onImpact-of-Deployment-on-Military-Children.pdf

Goodwin, G. (2008). Psychology in sports and the military: building understanding and collaboration across disciplines. Military Psychology (Taylor \& Francis Ltd), 20, S14753.

Hawkins, B. L., Cory, A., \& Crowe, B. M. (2011). Effects of participation in a Paralympic military sports camp on injured service members: Implications for therapeutic recreation. Therapeutic Recreation Journal, 45(4), 309-325.

Hibbard, M. R., Uysal, S., Sliwinski, M., \& Gordon, W. (1998). Undiagnosed health issues in individuals with traumatic brain injury living in the community. The Journal of Head Trauma Rehabilitation, 13(4), 47-57.

Kingsbury, A. (2010). The military option. U.S. News \& World Report, 147(10), 40-43. Koebler, J. (2012, May). New prosthetics keep amputee soldiers on active duty. US News. Retrieved from http://www.usnews.com/news/articles/2014/2/20/newprosthetics-keep-amputee-soldiers-on-active-duty

Lundberg, N., Bennett, J., \& Smith, S. (2011). Outcomes of adaptive sports and recreation participation among veterans returning from combat with acquired disability. Therapeutic Recreation Journal, 45(2), 105-120. 
Machida, M., Irwin, B., \& Feltz, D. (2013). Resilience in competitive athletes with spinal cord injury: The role of sport participation. Qualitative Health Research, 23(8), 1054-1065. doi:10.1177/1049732313493673

Miles, M., B., \& Huberman, A., M. (1994). Qualitative data analysis. Thousand Oaks, CA: Sage Publications.

Moustakas, C. E. (1994). Phenomenological research methods. Thousand Oaks, CA, US: Sage Publications, Inc.

Obama, B. (2009, January). Inaugural address by President Barack Obama. Washington, D.C..

Osran, H. C., Smee, D. E., Sreenivasan, S., \& Weinberger, L. E. (2010). Living outside the wire: Toward a transpersonal resilience approach for OIF/OEF veterans transitioning to civilian life. Journal of Transpersonal Psychology, 42(2), 209235.

Paterson, B., \& Scott-Findlay, S. (2002). Critical issues in interviewing people with traumatic brain injury. Qualitative Health Research, 12(3), 399-409.

Patton, M. (2002). Qualitative evaluation and research methods. Thousand Oaks, CA: Sage Publications.

Perrier, M., Smith, B., Strachan, S. M., \& Latimer-Cheung, A. E. (2014). Narratives of athletic identity after acquiring a permanent physical disability. Adapted Physical Activity Quarterly, 31(2), 106-124.

Pew Research Center. (2011). Military-civilian gap: War and sacrifice in the post 9/11 era. Retrieved from http://www.pewsocialtrends.org/2014/02/05/war-andsacrifice-in-the-post-911-era/ 
Richmond, T. S., Thompson, H. J., Deatrick, J. A., \& Kauder, D. R. (2000). Journey towards recovery following physical trauma. Journal Of Advanced Nursing, $32(6), 1340-1347$.

Deci, E. L., \& Ryan, R. M. (1985). Intrinsic motivation and self-determination in human behavior. Springer Science \& Business Media.

Ryan, R. M., \& Deci, E. L. (2000). Self-determination theory and the facilitation of intrinsic motivation, social development, and well-being. American Psychologist, 55(1), 68-78. doi:10.1037/0003-066X.55.1.68

Ryan, R. M., \& Deci, E. L. (2012). Multiple identities within a single self: A selfdetermination theory perspective on internalization within contexts and cultures. In M. R. Leary, J. P. Tangney, M. R. Leary, J. P. Tangney (Eds.), Handbook of self and identity (2nd ed.) (pp. 225-246). New York, NY, US: Guilford Press.

Ryan, R. M., Williams, G. C., Patrick, H., \& Deci, E. L. (2009). Self-determination theory and physical activity: The dynamics of motivation in development and wellness. Hellenic Journal of Psychology, 6(2), 107-124.

Rolls, C., Inglis, A., \& Kristy, S. (1997). Study abroad programs: creating awareness of and changing attitudes to nursing, health and ways of living in other cultures. Contemporary Nurse, 6(3-4), 152-156.

Seidman, I. (1998). Interviewing as qualitative research: A guide for researchers in education and the social sciences (2nd ed.). New York: Teachers College Press.

Smith, R. T., \& True, G. (2014). Warring identities: Identity conflict and the mental distress of American veterans of the wars in Iraq and Afghanistan. Society and Mental Health, doi: 2156869313512212 
Tedeschi, R. G., \& McNally, R. J. (2011). Can we facilitate post-traumatic growth in combat veterans?. American Psychologist, 66(1), 19-24. doi:10.1037/a0021896

Thoits, P. A. (1992). Identity structures and psychological well-being: Gender and marital status comparisons. Social Psychology Quarterly, 55(3), 236-256.

Thoits, P. A. (2013). Self, identity, stress, and mental health. In C. S. Aneshensel, J. C. Phelan, A. Bierman (Eds.), Handbook of the sociology of mental health (2nd ed.) (pp. 357-377). New York, NY, US: Springer Science + Business Media.

Thoits, P. A. (2011). Volunteer identity salience, role enactment, and well-being: Comparisons of three salience constructs. Social Psychology Quarterly, 76(4), 373-398. doi:10.1177/0190272513498397

Toblin, R. L., Riviere, L. A., Thomas, J. L., Adler, A. B., Kok, B. C., \& Hoge, C. W. (2012). Grief and physical health outcomes in U.S. service members returning from combat. Journal of Affective Disorders, 136(3), 469-475. doi:10.1016/j.jad.2011.10.048

U.S. Paralympics, (n.d.). U.S. Paralympics Military. Retrieved from http://www.teamusa.org/us-paralympics/military

Weisskopf, M. (2007). A grim milestone: 500 amputees. Retrieved from http://content.time.com/time/nation/article/0,8599,1580531,00.html

Williams, A., Ericsson, K., Ward, P., \& Eccles, D. (2008). Research on expertise in sport: implications for the military. Military Psychology (Taylor \& Francis Ltd), 20S123-45.

World Class Athlete Program. (n.d.). Retrieved from http://www.thearmywcap.com/\#!paralympics/c1viv 
Table 1

Participants' military career timeline

\begin{tabular}{lllll}
\hline Name & $\begin{array}{l}\text { Military experience } \\
\text { prior to deployment }\end{array}$ & $\begin{array}{l}\text { Deployment } \\
\text { length pre-injury }\end{array}$ & $\begin{array}{l}\text { Post-injury } \\
\text { rehabilitation }\end{array}$ & $\begin{array}{l}\text { Time in TSU } \\
\text { to date }\end{array}$ \\
\hline Gabriel & 5 years & 3 months & 1 year & 2 years \\
Juan & 1 year & 3 months & 1 year & 1 year \\
Cameron & 2 years & 3 months & 2 years & 3 years \\
William & 7 years & 9 months & 2 years & 10 years
\end{tabular}




\section{Appendix A}

\section{Review of Literature}

This literature review is separated into six separate parts detailing previous research in the areas of (a) identity of service members, (b) formation of soldier identity, (c) acquired disabilities (d) physical activity and sport participation for individuals with acquired disabilities (d) identity formation, (e) re-establishing identity through sport (f) summary.

\section{Identity of U.S. Service Members}

Military engagement is the oldest and most dangerous form of public service in the United States. Historically, military service had been a requirement rather than a choice. However, since the last military draft occurred in 1973, the US has fought all conflicts entirely by professional military and enlisted volunteers (PEW, 2011). Not surprisingly, the transition to an all-volunteer military dramatically influenced enlistment rates. In fact, the percentage of Americans who have participated in active duty has dramatically decreased from $9 \%$ in 1942 to just $0.5 \%$ over the last decade (PEW, 2011). With reduced enlistment, an all-volunteer military required change in the infrastructure to remain efficient and effective and correspondingly so did the identity of its service members. The Army's updated Creed portrays the modern day soldier as a professionally trained 'warrior' and guardian of freedom who is physically and mentally tough, always prepared and places the mission first (Smith \& True, 2014).

The attacks on New York City on September 11, 2001 marked the beginning of the war on terrorism. For many Americans, the appeal of becoming a service member is often about the opportunity to serve their country and be apart of something greater than one's self. The impact 9/11 had on the American people was seen in Armed Forces 
recruitment increases among males aged 16-21 upwards of 8\% immediately following the attacks. The enlistment numbers remained exceptionally high through until 2005, but has yet to fall below the annual recruitment goal (DOD, 2013). Between the 9/11 attacks and 2013, 3.3 million Americans have proudly enlisted voluntarily to serve their country in Operation Enduring Freedom (OEF) and Operation Iraqi Freedom (OIF) (DMDC, 2013). Patriotism has consistently ranked as one of the top three reasons to enlist since the beginning of the war on terrorism. Additional reasons include: independence, job security, travel opportunities and education (PEW, 2011). The recruitment of passionate Americans to join the all-volunteer military force has been successful over the past decade, but the changes towards more modern warfare tactics have been necessary to continue the war on terrorism with a decreased military force by $30 \%$ as compared to twenty years ago at the end of the Cold War (PEW, 2011). Although some of these changes have produced a smarter, more efficient and effective unit, the longevity of the war has now exceeded a decade, requiring service members to endure multiple deployments. With involvement in wars in two countries and peacekeeping throughout the world, service members have been deployed to volatile combat zones for longer periods and more frequently than historically noted.

Although the organizational structure and operation of the military in the United States has been forced to evolve to meet the modern day needs of the country, the pride of service has not been tarnished. In 2011, Pew Research Center surveyed 1853 men and women who served in the military and are no longer on active duty. The findings indicated that almost all veterans were proud of their service, with $80 \%$ indicating that they would encourage youth to consider a career in the military. When reflecting upon 
the intrinsic benefits, several different character traits emerged. Ninety percent of veterans who served post $9 / 11$ felt their service in the military provided an increased sense of self-confidence, increased ability to work with others, as well as develop maturity. Seventy-two percent indicated that their service helped prepare them for a post military career.

\section{The Formation of Soldier Identity}

The motivational underpinnings, which inspire Americans to join the military, are just the beginning of the transformation process from civilian to soldier. The success of military efforts relies on the conformity of service members to rigorous standards of collectivism, obedience and regimentation (Smith \& True, 2014). This assimilation to 'total institution' begins with 10 weeks of mandatory of intensive basic combat training (BCT), which serves as the initial transformation from civilian to soldier. During these three months, soldiers embark on a journey of conformism founded in core values designed to unite through physical and mental challenges. The soldier identity further develops upon deployment, where units are reliant upon each other for safety, protection and survival. Vest (2012) interviewed 48 National Guard members who either had or had not been deployed to understand the identity negotiations, which transpire for military reserve members. Findings indicated that those with deployment experience more strongly aligned with a 'soldier-warrior' identity than those who had not deployed. This suggesting that the identity and sense of self of service members intensifies with the immersion in combat experience. Osran, Smee, Sreenivasan and Weinberger (2010), describe modern warfare as an'asymmetrical battlefield' where soldiers are barraged with countless hidden explosives and safe military bases are exposed to mortar and rocket fire. 
These experiences and stressors unique to the conditions of the battlefield, bring soldiers together in a family-like bond.

Physical aspects. Physical prowess is defining attribute of the soldier self. Combat readiness requires soldiers to be mentally and physically prepared for extreme situations, in various conditions and climates. Conditioning the body, 'train as you fight' is one of the Army's core training components, which is initiated in basic training and maintained through mandatory physical training (PT) throughout a soldier's career. Similarly to an elite athlete utilizing a tailored and periodized training regimen in preparation for competition, military service member are subjected to specialized training in preparation for deployment. This specialized training is designed to emulate the physical movements and demands under similar conditions to the battlefield, which will be required for combat missions.

Psychological aspects. Bates and colleagues (2010) additionally highlight the evolution of warfare and the vital importance of cultivating the specific psychological traits to build resilience in soldiers to best prepare them for current military operations. In an effort to gain understanding of the dispositions and psychological traits relevant to successful military adjustment, Rydstedt and Osterberg (2013) assessed the personality traits, psychological fitness and hardiness of individuals in the Swedish Armed Forces (SAF). This exploratory study specifically examined service members who volunteered for international peacekeeping missions as compared to those who did not volunteer. The findings reported no significant differences between the two groups in terms of personality traits such as independence, uniformity and temper stability. However, significant differences were found in terms of self-efficacy and stress tolerance. Service 
members who volunteered for peacekeeping missions reported higher levels of selfefficacy and stress tolerance, which have previously been identified as important components of psychological fitness and hardiness required for success in combat situations (Bartone, 2006).

The connection between the mind and body is of utmost importance to the achievement and sustainability of military service members in preparation for combat missions. To perform or achieve at an expert level, psychological skills are imperative (Williams \& Ericsson, 2005). Hammermeister, Pickering, McGraw and Ohlson (2010) used a modified version of the Ottawa Mental Skills Assessment Tool-3 (OMSAT-3) to measure psychological skills in 427 soldiers from US Army's Stryker Brigade and assessed whether differences in psychological skill profiles were related to performance on the Army Physical Fitness Test (APFT). The results of the study reveal an insightful perspective on the mind-body connection for soldiers during physical fitness testing. Of the three distinct psychological skill profile groups which emerged (strong, weak and fear/fail/focus), soldiers in the strong psychological skills group significantly outperformed their peers in the APFT (Hammermeister, et al, 2010). Empirical evidence connecting psychological traits to soldier's physical performance is limited, but Hammermeister, Pickering, McGraw and Ohlson (2010) found parallels, which exist within sports psychology literature on athlete performance, which can inform the discussion on soldier performance.

Unique challenges. The experiences that unify soldiers on the battlefield also pose unique challenges upon returning stateside following a combat mission. The transition from a 12 to 15 month-long adrenaline fueled perilous deployment back to a 
civilian lifestyle can be arduous. Although the support of loved ones may be present, few can truly understand the uniqueness of the operation (Danish and Antonides, 2013). Military culture instills pride in service members, who in turn have a strong desire to view their work as meaningful and valued. Fighting for your country is the ultimate sacrifice and embodies the essence of a warrior. Upon returning from deployment, away from the intensity of battlefield, the normalcy of domestic life can challenge one's sense of purpose.

The psychological challenges experienced by veterans from OIF/OEF have been the focal point of much research over the past decade. Danish and Antonides (2013) propose that the majority of distress service members experience occurs upon return from deployment during their struggles to reintegrate to domestic life. The authors use work of mythologist Joseph Campbell (1949) who believed that myth had parallels in the real world and provided framework for understanding life's passages. Specifically, attention was directed towards the life journey of the mythical hero, which mirrors that of the modern day, all-volunteer service member. The beginning stage of separation is fueled by desire to pursue a higher calling, which is followed by initiation of enduring tests of resilience and self-sacrifice, which provides meaning to the mission. The final phase of return may challenge the hero/soldier, as the 'former world' may not understand what they have endured and learned through the experience. Danish and Antonides (2013) believe that many soldiers return from a deployment with a newly discovered sense of self founded in the accomplishments of the mission in which they served. The challenge becomes the adjustment to apply these newly founded skills and traits within a new environmental context. The American military system excels at training soldiers to be 
physically and mentally prepared for combat. Unfortunately, the repercussions of this preparation are the "Army Strong" mentality, a mindset which may also deter soldiers from seeking help psychological help when needed (Danish \& Antonides, 2013).

Orsan, Smee, Sreenivasan and Weinberger (2010) provide an alternative perspective on "living outside the wire" and discusses the need to help soldiers maintain emotional, spiritual and physical wellness transition to domestic life. The authors suggest a framework based on the work Viktor Frankl that transpired from his quest for survival during his imprisonment in a Nazi concentration camp. Specifically, Orsan, Smee, Sreenivasan and Weinberger (2010) focus on components of Frankl's work which relate to a proposed framework for the development of a transpersonal oriented resilience approach for transitioning veterans to civilian life. It is implied that service members returning from war re-evaluate the transpersonal motivation of being apart of something greater than themselves. During this period, individuals may experience existential vacuum, which refers to a lack of purpose or emptiness in one's life. The authors connect life in the concentration camp, to life on the battlefield, where meaning is derived from survival. Upon returning from such hardship, the maintenance of the resilience qualities that embodied the soldier in combat, need to be nurtured. For effective transition using a resilience approach, emphasis should focus on the combat experience but which is placed within a meaningful life-context (Osan, et al., 2010).

Recent reports have shown that more than half of veterans who have participated in post 9/11warfare have reported difficulty reintegrating into civilian life (PEW, 2011). Although much research has evaluated the psychological problems of veterans post deployment, few efforts have focused on the transformative identity of soldiers 
reintegrating into civilian life. Smith and True (2014) examined the struggles of readjustment to civilian life as experienced by 26 service members after returning from combat missions as a part of OIF and OEF. The study focused specifically on the identity conflict that is experienced from soldier to civilian. The unique experiences associated with being a military service member enhance identity and cultivate selfperception. This is especially relevant to the modern all-volunteer military.

Smith and True (2014) suggest that through combat exposure, the soldier's sense of self is converted to sense of 'bonded selves' that is no longer individualized. The cohesion of the unit is sewn through a common goal, which requires soldiers to be regimented and resilient under the fiercest conditions. In the sample of combat soldiers studied, most felt more control in their role within a combat zone, than they did upon return to civilian life. The return to autonomous way of life presented an overwhelming variety of variables, which most found difficult to navigate after a life of order and hierarchical structure. The findings also indicated that the stronger the commitment to the soldier identity, the more difficult the challenge to transition to civilian life.

Toblin, Riviere, Thomas, Adler, Kok and Hoge (2011) surveyed 1522 soldiers six months following return from deployment in an effort to identify the prevalence of postdeployment health concerns, as well as determine the level of difficulty coping with grief. Of the sample surveyed, $92 \%$ were male and $73 \%$ were under the age of 30 . The results of the study found the majority of soldiers surveyed reported experiencing at least one physical health problem such as difficulty sleeping, musculoskeletal pain, fatigue, back pain or headaches. Additionally, one in five soldiers reported difficulty coping with grief over the loss of a comrade. After controlling for demographic variables, grief 
significantly correlated with the physical well-being and occupational impairment outcomes of soldiers post-deployment. This research emphasizes the interconnectedness of the mind and body and need to address both during post-deployment.

\section{Acquired Disabilities}

As of 2011, the number of Americans living with a disability was over 37 million, equaling $12.1 \%$ of the U.S. population (U.S. Census Bureau, 2011). Veterans permanently injured as a part of their military service account for $19.1 \%$ of all disabled Americans. While one in four Americans will acquire some form of disability between the ages of 21 and 64 (Social Security Administration, 2011), for active duty soldiers, one in six will experience a serious injury in combat since (PEW, 2011).

Psychological implications. Most disabilities in the American population are acquired through poor health, disease, fitness practices, violence and other accidents that occur during a person's lifespan (Sherrill, 1997). Fewer than 15\% of classified individuals are actually born with a disability (Sherrill, 1997). Research as found that individuals with acquired disabilities often struggle to adjust to their disability than individuals with congenital disabilities ( $\mathrm{Li} \&$ Moore, 1998). The ability to adjust and accept the disability has been linked to the age of onset. The later in the life the disability is acquired, the more difficult it becomes for the individual and family members accept the disability (Sherrill, 1997). Individuals with acquired disabilities (IAD) experience a variety of secondary physical and psychological conditions that may further limit their abilities and ultimately influence the level of disability experienced (Ravesloot, Seekins, \& Walsh, 1997). The onset of an acquired disability challenges individuals to tackle the physical and psychosocial constraints, which ultimately impact self-perception. 
Newly acquired disabilities can dramatically impact an individual's psychological state, which in turn directly influences the rate and success of rehabilitation (Larner, 2005). Post injury, individuals immediately begin to negotiate a redefined sense of self, which is often mediated by the personal meaning of disability, not the disability itself (Wright, 1983). The stigma associated with being a part of a minority group can leave attitudes, emotional state and anxiety levels in flux, especially within the first two years of onset. Approximately $25 \%$ of individuals with acquired disabilities experience depression in the immediate years following the onset of disability (Hahn, Aronow, Rasario \& Guenther, 2013; Fann, Hart \& Schomer, 2009).

Sixty-five percent of OEF and OIF service members wounded in action were injured by blasts and fragments from improvised explosive devices, land mines and other explosive devices. As a result, it is estimated that $28 \%$ also acquired some degree of traumatic brain injury (Bascetta, 2007). These complex injuries require comprehensive rehabilitation to address both the cognitive and physical injuries as well take preventative measures to avert the development of mental health impairments.

For soldiers, the experiences shared in combat create profound unity. Cultivated from the essential need to rely upon others for safety and protection, united in a purpose much greater than one's self. The aftermath of a sustained injury is often much greater than what seen on the surface. Returning home from deployment can be an adjustment for most military professionals, but for those who face uncertainty in their profession due to injury, the reclamation process becomes daunting (Osran, Smee, Sreenivasan \& Weinberger, 2010). 
Physical implications. Although twelve percent of the American population has a disability, their needs, interests and aspirations are no different to their able-bodied peers (Temple \& Walkley, 2007; Sherrill, 1996). Yet the life experiences of these individuals are often marginalized through the exclusion of ordinary relationships and everyday activities. Fifty percent of individuals with acquired disabilities lead a sedentary lifestyle and are considered high risk for obesity (Brown, Yore, Ham, \& Macera, 2005; Martin, Ginis et al., 2010). According to the Healthy People 2010 report $56 \%$ of adults with disabilities live a sedentary lifestyle and do not participate in the recommended 150 minutes of physical activity per week (CDC, 2012). The benefits of physical activity participation are universal for all individuals and essential to maintaining physical and mental fitness (Martin, Ginis \& Hicks, 2007; Murphy \& Carbone, 2008). After acquiring an injury the importance of regular fitness becomes even more important in an effort to prevent physical complications associated with inactivity (Brittian, 2012).

Prior to World War II, the majority of individuals who had acquired a major disability such as a spinal cord injury died within three years (Brittain, 2012). The development of new medications in the 1930's meant there was new hope to prolong the life expectancy of those with traumatic injuries (Brandmeyer \& McBee, 1986). Unfortunately, this caused additional complications created by the societal attitudes towards disabilities. Dr. Lugwig Guttmann, a German neurologist who sought asylum in England, became the Director of the National Spinal Injuries Unit in Stoke Madneville, Ayesbury. It is here where he began using sport as a form of rehabilitation for soldiers with spinal cord injuries (Brittian, 2012). The sport programs were developed to give 
hope to the patients and foster a sense of self-worth. Additionally, Guttmann aspired for the program to change the attitudes of society; by showcasing athletes with spinal cord injuries leading productive lives within the community (Brittain and Green, 2012).

Since the World War II era, sport and exercise have been as valued a fundamental component of the rehabilitation process for wounded veterans. Guttmann's efforts brought adapted sport competition to the forefront with the Grand Festival of Paraplegic Sport in 1949, which eventually became the Paralympic Games (Brittain and Green, 2012). Guttmann's research and dedication to rehabilitating wounded veterans' lives on today in various military sports programs across the world.

Military initiatives for veterans with acquired disabilities. Recognizing the need to develop the pipeline of Paralympic athletes, US Olympic Committee (USOC) crafted a program that would tap into the largest pool of athletes with disabilities: the United States Armed Forces. In 2004, the US Paralympic Military Program (PMP) was launched, offering adapted sport opportunities for recently disabled veterans returning from Iraq and Afghanistan (Batts \& Andrews, 2011). Capitalizing on the rehabilitative advantages of sport, the PMP offers a unique opportunity for veterans to preserve the core values instilled through military service, however engaging in combat on a different platform. Nationwide clinics and camps have introduced veterans to the various adapted sports available through hands on learning by Olympians, Paralympians and certified coaches. The response to these programs has been overwhelming, with participation increasing from $31 \%$ to $54 \%$ within the past two years (US Paralympics, n.d.).

For those who wish to remain in the service by continuing on active duty or reserve, there are a few programs that allow service members to pursue athletic 
excellence full-time. The World Class Athlete Program (WCAP) provides support for training and competition at the elite level, while maintaining a professional military career. To achieve this status, soldiers must meet specific classification criteria and demonstrate potential to qualify for the U.S. Paralympic team through recognized competition results (WCAP, n.d.).

The well-established Target Sports Unit (TSU) is an additional avenue for service members interested in Olympic-style target sports. As master caliber marksmen, the service members in the unit train not only to excel in competition, they are elite instructors who train thousands of service members each year about the fundamentals of marksmanship. Originally established to raise the standards of marksmanship throughout the services. The TSU recruits the best marksmen in the military and showcases their talents through international competitions and demonstrations. As the unit evolved, the showmanship of the service members in the unit were used in recruiting efforts and additionally served as master instructors to improve marksmanship skills such as, precision and accuracy. In recent years, the TSU expanded to include a Paralympic section for individuals who meet the criteria and have the ambition and stamina needed to reach success on the international stage (U.S. Paralympics, n.d.).

Although there are many sport opportunities to meet the needs and interests of veterans, very few can be considered an avenue for those who wish to continue in the services and represent their country in elite sport.

\section{Recovery Through Sport: Benefits of Participation}

The benefits of physical activity for individuals with disabilities extend far beyond the playing field. Fundamentally, sport is a platform for increased physical 
competence, which promotes self-esteem and self-concept. Sport also affords the opportunity to foster socialization through peer interactions and developed friendships which individuals with disabilities struggle to obtain beyond their circle of support (Brittain \& Green, 2012). Independence can also be attained through the cultivation of self-identity, which reinforces a purpose in life (Murphy \& Carbone, 2008). Yet these benefits can only be achieved if the opportunities are made available. Participation is influenced not only by an individual's functioning ability, skills, interest and culture, but also their physical, social and institutional environments.

Psychological implications. Rehabilitation is the process of restoring the health for individuals who have acquired an injury in an effort to maximize their physical and psychological well being so they can continue to lead productive lives in society (Hutzler \& Bar-Eli, 1993). Traditional models of rehabilitation include medical, vocational, social and recreational interventions to reconnect the individual into the various environments needed for personal growth, independence and everyday life tasks (Hutzler \& Bar-Eli, 1993). Rehabilitation has been widely recognized and accepted as an essential recovery tool after acquiring an injury and more recently researchers have investigated additional psychological traits such as post-traumatic growth and resilience in groups of individuals who have acquired a disability.

Post-traumatic growth and resilience. Trauma can be defined as an event that profoundly affects an individual's life course, by altering personal beliefs, efficacy and lead to psychological stress (Van Sylke, n.d.). The negative impacts of trauma, including post-traumatic stress have been much of the concentration throughout much of the acquired disability literature (Hancock, Dickson, Chang \& Martin, 1993; Salick \& 
Auerbach, 2006; Smith \& True, 2014). With the on-going conflicts in the Middle East and the increased number of military service members returning with psychological challenges, researchers have been intrigued to explore those who have reported positive psychological changes following a traumatic event. This term has become know in the field as post-traumatic growth (PTG) and has been viewed as a coping mechanism, which can influence self-perception, interpersonal relationships and outlook on life (Crawford, Gayman, \& Tracey, 2014). PTG research has been studied on a variety of populations, including cancer survivors, emergency response personnel, automobile accident victims and injured athletes offering implications for military service members who have acquired injuries in combat (Crawford, Gayman, \& Tracey, 2014).

Historically, the military training efforts focused on the physical well-being of the service members and the tactical components of warfare (Tedeschi \& McNally, 2011). It has been only in recent years that psychological and emotional wellness been considered of importance for military preparation and also beyond. In an effort to promote resilience and enhance performance as a preventative measure, the US Army developed the Comprehensive Soldier Fitness (CSF) program. This program provides hands-on training and personal development tools to help soldiers and their families cope with adversity, perform at their best under pressure and thrive in everyday life (Comprehensive Soldier and Family Fitness, n.d.). Tedeschi and McNally (2011) believe a well-designed military program such as CSF can potentially promote PTG provided that programs place emphasis on the emotional, social and spiritual development of soldiers prior to deployment. Integrating these components within the mandatory training increase the 
possibilities for personal transformation and resilience to combat the stressors of the future within their military careers and beyond.

Within the physical activity and recreation literature, participation in sport has shown to facilitate both resilience and PTG in individuals after acquiring a disability (Crawford, Gayman \& Tracey, 2014; Day, 2013; Machida, Irwin \& Feltz, 2013). In a phenomenological study, Machida, Irwin and Fletz (2013) explored the role of sport participation on the resilience process of quad rugby players. Twelve male athletes with spinal cord injuries were recruited from a quad rugby tournament to participate. Semistructured interviews were employed to gain in-depth understanding of the life experiences associated with acquiring a spinal cord injury and the influence of sport on those experiences. The results indicated participation in sports for individuals with acquired disabilities provided opportunities, social supports and experiences. Teammates were considered an instrumental support system, especially helping to adjust to the injury both physically and psychologically. Participation in sports also promoted vicarious learning, where individuals developed adapted life skills and coping strategies. Participants indicated that success in sport increased their self-confidence and was also an opportunity to convert negative sentiments into positive energy on the playing field. The foundations of participating in a team sport in this instance, showed resilience can be developed after acquiring an injury. In addition, sport offers a platform to rebound from adversity and allow for PTG to potentially take place.

Day (2013) recently found growth after and injury to be both achievable and meaningful, for a group of Paralympic athletes. Connecting the ideals of the Paralympics, Day (2013) explored the role that physical activity played in the 
development of post-traumatic growth among of seven Paralympic athletes. The coping and recovery strategies employed after a traumatic experience can influence the ability to find meaning and grow from experiences. From the data, three primary themes emerged which outlined transformative experiences post injury. The first represented the realization of the acquired disability and the immediate limitations that ensued, along with the struggle to comprehend the new life that had presented itself. The second theme identified represented the responsibility for choice and consequences that began during the recovery stages. Physical activity may have begun as a form of rehabilitation, but challenged the participants to achieve skill mastery. Success became a motivational factor to seek further challenges and sporting opportunities. During this period, the participants also gained understanding of the risk associated with their disability and sport participation. From this grew ownership of the health consequences associated with participation in their chosen sport. Finally, the data suggested that participation in physical activity and sport was a vehicle for re-establishing meaning within each participant's life.

Motivation. Understanding why people choose to participate in sport after acquiring a disability has been the center of much research over the past twenty years. Page, Edmund, O’Connor and Peterson (2001), conducted a qualitative study on six elite athletes with disabilities to explore their underlying achievement motivation. Semistructured interviews were conducted, using modified questions from the Sport Orientation Questionnaire (Giller \& Deeter, 1988). Questions targeted motivation as it relates to (a) competitiveness, (b) the desire to win in interpersonal competition in sport, and (c) the desire to reach personal goals in sport. 
Findings from the data revealed three key themes, which address the reasoning for pursuing sport at a high level: (a) other people, (b) sport as a social outlet, (c) sport as a source of activity. From the data it was found that the perceptions from others motivated the participants to compete in sport. The ability to perform and demonstrate skill competency and proficiency in the presences of others gave participants the sense of empowerment. In addition, success in sport was viewed as a vehicle to negate the negative attitudes often associated with disabilities. The second theme, which emerged focused on the social aspect of belonging to a team and the sense of camaraderie, which accompanies a team dynamic. Another interesting finding suggested that athletes with disabilities felt they shared a special culture that others may not comprehend. Individuals with disabilities who engage in sport embrace their differences and are able to connect through shared experiences and a distinct language with unique meanings. The final theme aligned with findings from previous research related the benefits of participating in sport and physical activity. Physical activity was seen as a vital component of maintaining a healthy lifestyle, both physically and mentally. Participants described how PA helped to combat fatigue, depression and provided physical conditioning, which made everyday tasks easier, fostering independence (Page, Edmund, O’Connor \& Peterson 2001). The findings of this research indicate that sport is a vehicle for leading a healthy lifestyle, with benefits experienced not only just in the context of sport, but throughout one's everyday life.

In a resent study conducted by Molik, Zubala, Slyk, Bigas, Gryglewicz and Kucharczyk (2010), Paralympic athletes were surveyed to investigate their motivation to participate. Data was collected from a group of 174 male and female athletes who 
participated in boccia, wheelchair rugby or wheelchair basketball. Interestingly, the motivational factors varied across the various sporting disciplines. The results found that maintaining physical fitness and teamwork were prevalent with the wheelchair basketball participants. Wheelchair rugby players rated physical fitness and the opportunity to build skill competency highest. While the athletes who participate in boccia indicated that the sport was a form of therapy. The wheelchair basketball and rugby player also indicated that sport provided them an opportunity for achievement and recognition. This research contributes to the body of knowledge on the benefits of sport participation for individuals with disabilities, but additionally contends that Paralympic sport is no longer just viewed as a form of rehabilitation.

Psychosocial. The psychosocial benefits of participation in sport for individuals with disabilities has recently emerged as field of interest for researchers in the last two decades, yet very few studies have explored that of elite caliber athletes (Jefferies, Gallagher \& Dunne, 2012). In a recent review of literature composed by Jefferies, Gallagher \& Dunne (2012), 16 peer reviewed journal articles were systematically analyzed in an effort to gain knowledge regarding the psychosocial attributes of Paralympic athletes. The findings of the study indicated that athletes competed for various reasons from friendship to fitness to social status, primarily based upon their gender or country of origin. Paralympic athletes did however indicate that their teammates and coaching staff were much like a second family. The time spent together, along with the motivation to achieve the same goal, united the athletes and staff.

Lundberg, Bennett and Smith (2011) investigated the quality of life (QoL) of OIF/OEF veterans who participated in adapted sport programs. A total of 18 veterans 
who were registered for a weeklong therapeutic sports camp in Idaho agreed to participate in the study. Participants were surveyed prior to the camp and at the conclusion of the camp. Findings reported no significant difference in the QofL of the participants from the beginning to the end of the sports camp. It was noted however, that participants had increased perceived self-confidence, and reduced stress, anger and depression.

Similarly, Hawkins, Cory and Crowe (2011) explored the effects of participation in a U.S. Paralympic Military Sports Camp on injured veterans, using a phenomenological lens. Data was collected through in-depth, semi-structured interviews of ten service members participating in the camp. Interview questions were selected to prompt participants to discuss their lived experiences of the camp and other life contexts. From the analyzed data, seven distinct themes emerged which included: (a) perceptions of disability and normalization, (b) motivation, (c) social connections, (d) establishing a connection with previous interests, (e) improved competence, (f) improved health, (g) increased autonomy. These findings bring to light the connections back to the soldierself. Participants describe the camaraderie between teammates at the sports camp because of their unique shared life experiences. Many indicated their experience at the camp inspired motivation to achieve something greater. Having the opportunity to recognize one's own potential had a profound impact on the veterans' outlook upon the conclusion of the camp. The actual exposure to competition rekindled connections to interests and determination prior to injury. Skill competence and competition allowed many to see themselves first and not their disability. 
The psychological response to acquiring an injury varies from person to person and often requires reassessment of personal life goals and perspectives (Van Sylke, n.d.). Studies have shown that psychosocial and demographic factors are associated with positive outcomes following a traumatic event (Burke and Utley, 2013). Different approaches to rehabilitation have been implemented over the years, many which involve sport and recreation initiatives. Burke and Utley (2013) explored the psychosocial responses to scaling Mt. Kilimanjaro for veterans who had recently acquired a disability in combat. Four male veterans with orthopedic injuries, ranging in age from 22 to 44 years participated in the climb. All participants described their injury as a difficult lifechanging event, which made them question their physical capabilities.

Various themes were uncovered from this ethnographic, multi-case study. The participants indicated that they believed that they could complete the task and anticipated being successful, representing a theme of self-determination and commitment to the goal. Climbing the mountain provided new physical and mental challenges for the veterans, which forced each participant to engage in active coping. Although no one had previous mountaineering experience, each had to negotiate coping strategies and take acceptance for what had happened to them in an effort to reach the peak. The final theme to emerge was social support. The men were unified in their goal and actively relied on each other for motivation. It was evident that the group approached the challenge as a team. Not surprisingly, all themes that emerged had similar aspects to those associated with military service and it was evident that previous military training helped the veterans accomplish the climb. Completing the climb helped the veterans regain a sense of normalcy because of the strong associations with their past responsibilities in the military. The results of 
this study indicate a need to provide opportunities for veterans that emulate the challenge and rigor often experienced in a military occupation.

\section{Formation of Identity}

The lived experiences and how those specific social interactions are personally interpreted help answer the question "Who am I?" Personal reflection is made from the perspective of one's self, other people and the general community (Thoits, 2013). A sense of self and identity are often used interchangeably, but distinction should be clarified between "self" and "identity." The aspect of a person that has experiences and acts lived experiences through self-interpretations of is often considered "the self" (Gecas \& Burke, 1995). Additionally, "the self" is most frequently perceived to be singular. As innately social beings, humans also behave in terms of socially defined categories or social selves, also known "identities." Identities are considered to be more specific understandings of self and experiences in relation to our society (Thoits, 2013). Identities are foundational components, which help define an individual's sense of self. These components frequently refer to (a) social demographic characteristics, (b) groups or organizations belonged to, (c) social roles, and (d) personality characteristics (Thoits \& Virshup, 1997). For the purpose of the proposed study, the focus will remain on how identity/identities are negotiated and their influence on the well-being of the self.

It is suggested that an individual's sense of self is comprised of multiple identities, based on the various self-established or defined roles they possess. Not all identities are considered equal, but rather are organized into a hierarchy based on person importance (Thoits, 2013). How others perceive a role, competency in the role, as well 
as intrinsic and extrinsic gratification can additionally influence the value placed on a specific identity (Thoits, 2013).

Taking a symbolic integrationist perspective, Thoits (2013) suggests that social identities, especially based on social roles can have significant influences psychologically. "When individuals invest themselves in their roles, they do not only do they gain a sense of who they are as meaningful social objects, but of what they do and how they behave in given situations, as well” (Thoits, 2013, p.362). Based on the feedback received from engagement in a role within a specific social environment, anxiety and stress may be reduced and self-esteem can potentially increase as suggested by Ahrens and Ryff (2006) and Barnett and Hyde (2001).

The value placed on a particular identity could potentially change over time. Lived experiences, especially those negative consequences can alter the salience of a specific identity. Therefore leading to potential negative mental health consequences, such as anxiety, depression and stress (Thoits, 1995). Burke (1991) proposed that when identities are established, a four-part feedback loop is activated which essentially moderates the centrality of the identity. The loop is comprised of (a) standard or set of self-meanings, (b) input from the environment, (c) process that compares or comparator, (d) output, meaningful behavior. This process suggests that individuals negotiate identities based on a sense of meaning. These established identities are then compared with a social standard within the environment by self-appraisal, which in turn influences behavior. This process in considered to be on-going and therefore individuals are constantly mediating their identities. Burke (1991) suggests that external events can potentially break the cycle and a loss of identity can occur. In this instance, the impact 
can be severe enough for the individual to question "Who am I now?" Often loss of identity takes place when the standard is no longer valid (e.g. the loss of a job or acquiring a disability).

A traumatic event can also be a catalyst for personal growth, based on the personal meaning of the event, as it relates to a specific identity. Bernard, Whittles, Kertz and Burke (2014) found that exposure to a traumatic event does not necessarily have negative mental health consequences, but rather dependent upon the significance of the event to the individual. The findings also indicated that positive experiences with personal meaning have the potential to influence resilience and coping strategies when an individual is exposed to a traumatic experience. These findings have implications that can inform the literature on the mental health and identity of veterans recovering from a traumatic injury. It is imperative to acknowledge that each traumatic event will hold a different meaning to each individual and therefore researchers should consider investigating the life contexts and experiences in which the traumatic event occurred.

\section{Re-establishing Identity Through Sport}

It has often been said that sport is a microcosm of society. What is learned from the playing field can be applied within the context of everyday life. It has been used as a platform for change and development, as well as promotes peace and unity worldwide (Dyck, 2011). In a study conducted in Sierra Leone, Dyck (2011) used the sport football to re-integrate a group of teenaged ex-militants from various forces back into the community following a civil war. The children forced into warfare in Sierra Leone suffered from stress, anxiety, fear and depression. Interventions were taken in an effort to detach the young ex-soldiers from their military identity. During the football camp, 
the participants initially relied on their military skills, training and violence to establish their dominance, but by the end they reported building social relationships and support networks. From this study, it can be implied that sport is an effective environment to promote personal change and also build relationships with others who have shared similar experiences. Additionally, football was an appropriate choice of sport to promote reintegration because of its popularity across the country.

Although the benefits of physical activity are well known, Anderson (2004) suggests that an individual's physical self-concept plays a significant role in the development and maintenance of fitness, sport and activity patterns. Anderson (2004) designed an instrument to measure athletic identity based on four dimensions derived from an existing body of literature. The scale measured the self-knowledge of athletic identity including: athletic appearance, importance of participation, skill competence and social support. Although the four dimensions were found to be of equal importance for defining athletic identity, the results reported the strongest correlations between importance and physical activity. The author concludes with suggestions for further research to include different demographic populations and also investigate athletic identity during life transitions.

Perrier, Sweet, Strachan, Latimer-Cheung (2012) explored the concept of athletic identity as a predictor of intention to participate in sport for individuals with acquired disabilities within the framework of the Health Action Process Approach (HAPA). The HAPA model is structured using two stages: the motivational phase and the volitional phase and is a framework often used to inform potential interventions. The motivational stage takes into account the internal variables that may influence intensions, such as self- 
efficacy, perceptions of risk and outcome expectations. In the volitional phase, the intensions set by the individual become actions of behavior.

The findings of the study indicated that for future interventions should place emphasis on the benefits of sport and physical activity, rather than the health concerns of leading a sedentary lifestyle. Self-efficacy was identified as an important predictor of sport participation and should be targeted for future interventions. Athletic identity was additionally found to influence an individual's intentions to participate in sport. This could be an important implication to the development and maintenance of one's perception of self, which has shown to influence intentions to participate in sport and physical activities.

Several key publications have explored athletic identity of elite athletes with disabilities. Martin, Adams-Mushett and Smith (1995), used the Sport Orientation Questionnaire (Gill \& Deeter, 1988) and the Athletic Identity Measurement Scale (AIMS) (Brewer, Van Raalte \& Linder, 1993) to assess athletic identity and sport orientation of a group of 57 (30 males and 27 females) international youth swimmers with both acquired and congenital disabilities. Similarly to the findings by Van de Vliet, Van Biesen and Vanlandewijck (2008), this study found a relationship between athletic identity and competitiveness, suggesting that individuals with strong athletic identities had a strong desire to achieve success in sport. These individuals additionally conveyed the desire to set achievement based goals and the aspiration to achieve those goals.

A research effort conducted by Van de Vliet, Van Biesen and Vanlandewijck (2008) provided supporting evidence on athletic identity of elite caliber athletes with disabilities in Belgium. Athletic identity research on able-bodied athletes has been 
connected to improved physical health, stronger self-esteem, confidence and improved social relationships (Fox \& Corbin, 1989; Marsh, Perry, Horsely, \& Roche, 1995). Athletic identity has been identified as an important component of self-concept, which extends beyond sport participation and the athlete role. The purpose of the study by Van de Vliet, et al (2008), was to best describe athletic identity of 23 Flemish Paralympic athletes and 37 elite athletes with disabilities. Through surveys measuring athletic identity, physical self-perception and self-esteem, the researchers were able to compare their data to similar studies on athletes without disabilities. Data on each athlete was collected twice over a 10-month span leading up to the 2004 Athens Paralympic Games. The findings indicated that Flemish Paralympians and elite athletes with disabilities had comparable athletic identity scores to competitive college-aged athletes without a disability. However, it was noted that younger athletes with less experience had varied differences in self-perception. The higher the level of competition, the more the individuals associated their goals and everyday efforts to their identity as an athlete. Interestingly, the strength of athletic identity, self-esteem and physical self-perceptions were not influenced by athletic performance and maintained stability throughout the various points of investigation.

Perrier, Smith, Strachan and Latimer-Cheung (2014) sought to better understand how athletic identity is lost or re-established after acquiring a permanent physical disability. Eleven individuals took part in 60 minute long semi-structured interviews, which were then examined using a narrative analysis. Participants were purposively sampled based on their involvement in sport pre and post injury in an effort to maximize the variety of experiences and associations to athletic identity. The findings revealed 
three distinct narratives, which included; (a) non-athlete, (b) athlete as future self, and (c) present self as athlete.

The non-athlete narrative emerged from three participants who although participated recreationally in sport or physical activity prior to their injury, did not currently participate, nor did they have any intention to return to those activities post injury. Interestingly, the barrier or lack of interest stemmed from their perceived low body image and skill competencies. For one participant, it was difficult to comprehend achieving the same level of success after his injury and therefore he could not reconnect with his previous athletic identity.

The athlete as a future-self narrative emerged from four participants.

Interestingly, this group tended to focus more on behavior and less on body image or physical performance. The participants in this group had returned to sport after injury, but primarily with therapeutic intentions. Although they could not fully connect with their former athletic identity, each shared interest in returning to a former sport or trying new sports. Although the participants constantly made comparisons between their athletic identity and who they saw themselves as now, behavior change was the most predominant theme.

Finally, the present self as an athlete emerged with four participants. These individuals tended to focus on current goals and present behavior. Of specific interest, was that this group saw their pre and post injury selves as different people. In terms of their present athletic identity, competition and performance and skill competency were identified as important factors in re-establishing athletic identity as well as developing motivation and commitment. The participants of this group did not view athletes with 
disabilities any differently than athletes without disabilities. These individuals focused specifically on the characteristics of athleticism, such as the sacrifices, commitment and determination to excel.

The results of this study reveal ways in which individuals perceive themselves from pre-injury to present time. From this research, valuable insight into how individual perceptions of the body and performance can influence opportunities to cultivate athletic identity after acquiring a physical disability. Specifically, those who focused on the characteristics of an athlete had higher potential to re-connect with an athletic identity. In addition, this research found that individuals who had acquired their disability in their late teens or early twenties were most closely associated with a present self as athlete identity. The implications of this research suggest that individuals should be exposed to sport as early as possible after acquiring a disability, as part of their rehabilitation.

An investigation of psychosocial outcomes of an inclusive adapted sports course for military personnel was conducted by Carless, Peacock, McKenna and Cooke (2013). Eleven men agreed to be interviewed and life story narratives were analyzed to discover themes. The two emergent themes included: (a) "Bringing me back to myself", (b) "New rooms to explore”.

Results found a series of themes that allowed the participants to reconnect with their former sense of self that may have faded after acquiring the disability which fell under the category "Bringing me back to myself". Many felt that the week long experience of adventure training and learning to do things, allowed them to appreciate life and the ability to partake in the activities being offered, as opposed to sitting on the sofa for weeks at a time. In addition, the camp gave the participants a sense of purpose 
that was lost after acquiring the disability. The training aspect provided the participants with the skills to lead an active life. Exposure to the various activities helped inspire the participants to seek out opportunities in the future. An additional theme under this category was reconnecting with others. Many expressed the notion isolation following their injury. The training camp allowed participants the opportunity for re-immersion into the military culture, connecting with individuals with similar histories.

Findings connected to the second category "New rooms to explore", exposed a group of themes that explored future opportunities. Participants valued the new experiences and activities they were being exposed to. Part of that came from the treatment they received at the camp by the support staff. Participants indicated they felt appreciated and valued, which helped foster motivation and determination to succeed throughout the week of challenging activities. In addition, being surrounded by others who have similar and heroic stories to share, along with the united camaraderie pulled others from their mental struggles. Each participant had influence on the others. The personal challenges and desire to overcome the barriers, provided inspiration for others in the camp.

This research highlights the remarkable benefits of reconnecting veterans through sport. The results of this study provide insight into the possible connections between the soldier-self of the past and the present athlete-self. Although the span of the camp was only five days, the implications show the psychosocial benefits, which are possible under these conditions. Future research recommendations include inquiry with a longer-term sport experience.

\section{Summary}


It is evident that individuals who choose a career in the military develop traits unique to the culture, environment and conditions in which they work under. Increased combat exposure can strengthen cohesion within a unit over the duration of a deployment. A strong bond amongst a unit is build upon the need to rely on others for safety and protection, exposure to similar war-related stressors and being apart of something greater than themselves. All service members return home changed after experiencing combat first hand causing distress as they transition back to life state side. Those who have acquired a traumatic injury face even greater challenges. The current literature by Smith and True (2014) suggest that there may be connections between the identity and psychological distress for veterans. As many veterans struggle to reestablish their sense of self after a traumatic event. Sport has long been a component of the rehabilitation process for wounded veterans, but more recently sport has been viewed as a vehicle to help (re)establish identity. Currently body of literature provides limited information on the influence of long-term programs, and to date no research has been conducted on the small percentage of veterans who choose to continue their service on RADS status. 


\section{References}

Ahrens, C. J. C., \& Ryff, C. D. (2006). Multiple roles and well-being: Sociodemographic and psychological moderators. Sex Roles, 55(11-12), 801-815.

Anderson, C. B. (2004). Athletic identity and its relation to exercise behavior: scale development and initial validation. Journal Of Sport \& Exercise Psychology, 26(1), 39-56.

Barnett, R. C., \& Hyde, J. S. (2001). Women, men, work, and family. American psychologist, 56(10), 781 .

Bartone, P. T. (1999). Hardiness protects against war-related stress in Army Reserve forces. Consulting Psychology Journal: Practice And Research, 51(2), 72-82. doi:10.1037/1061-4087.51.2.72

Bascetta, C. A. (2006). VA and DOD Health Care: Efforts to Provide Seamless Transition of Care for OEF and OIF Service Members and Veterans: GAO-06794R. GAO Reports, 1.

Bates, M. J., Bowles, S., Hammermeister, J., Stokes, C., Pinder, E., Moore, M., \& Burbelo, G. (2010). Psychological fitness. Military Medicine, 175(Suppl 1), 2138.

Batts, C., \& Andrews, D. L. (2011). 'Tactical athletes': the United States Paralympic Military Program and the mobilization of the disabled service member/athlete. Sport in Society, 14(5), 553-568.

Baczurik, A. C. (2012). Just tri: examining the transformative experiences of women amputees who participate in paratriathlons (Doctoral dissertation, Clemson University). 
Bernard, J. D., Whittles, R. L., Kertz, S. J., \& Burke, P. A. (2014). Trauma and Event Centrality: Valence and Incorporation Into Identity Influence Well-Being More Than Exposure.

Brewer, B. W., Van Raalte, J. L., \& Linder, D. E. (1993). Athletic identity: Hercules' muscles or Achilles heel? International Journal Of Sport Psychology, 24(2), 237254.

Brittain, I. (2012). The Paralympic Games: from a rehabilitation exercise to elite sport (and back again?)... adapted from Brittain I, Green SE (2012) Disability sport is going back to its roots: Rehabilitation of military personnel suffering sudden traumatic disablement in the twenty-first century Qual Res Sport Exerc 4(2): 24464. International Journal Of Therapy \& Rehabilitation, 19(9), 526-530.

Brittain, I., \& Green, S. (2012). Disability sport is going back to its roots: rehabilitation of military personnel receiving sudden traumatic disabilities in the twenty-first century. Qualitative Research In Sport, Exercise \& Health, 4(2), 244-264.

Brandmeyer, G. A., \& McBee, G. F. (1986). Social status and athletic competition for the disabled athlete: The case of wheelchair road-racing. Sport and disabled athletes, $181-187$.

Brown, D., Yore, M., Ham, S., \& Macera, C. (2005). Physical activity among adults $>$ or $=50 \mathrm{yr}$ with and without disabilities, BRFSS 2001. Medicine \& Science In Sports \& Exercise, 37(4), 620-629.

Burke, P. J. (1991). Identity processes and social stress. American Sociological Review, 836-849. 
Burke, S. M., \& Utley, A. A. (2013). Climbing towards recovery: investigating physically injured combat veterans' psychosocial response to scaling Mt. Kilimanjaro. Disability \& Rehabilitation, 35(9), 732-739. doi:10.3109/09638288.2012.707743

Caddick, N., \& Smith, B. (2014). The impact of sport and physical activity on the wellbeing of combat veterans: A systematic review. Psychology Of Sport And Exercise, 15(1), 9-18. doi:10.1016/j.psychsport.2013.09.011

Joseph, C. (1949). The hero with a thousand faces. Princeton, NJ: Princeton University.

Carless, D., Peacock, S., McKenna, J., \& Cooke, C. (2013). Psychosocial outcomes of an inclusive adapted sport and adventurous training course for military personnel. Disability And Rehabilitation: An International, Multidisciplinary Journal, 35(24), 2081-2088. doi:10.3109/09638288.2013.802376

Chan, C., Fung, Y. L., \& Chien, W. T. (2013). Bracketing in phenomenology: only undertaken in the data collection and analysis process. The Qualitative Report, $18(59), 1-9$.

Chockalingam, N., Thomas, N., \& Duval, L. (2012). Should preparation for elite sporting participation be included in the rehabilitation process of war-injured veterans? Prosthetics And Orthotics International, 36(3), 270-277. doi:10.1177/0309364612447096

Cocquyt, M., \& Sigmund, E. (2011). The impact of competition in physical activity and sport on the self-perception of individuals with physical disabilities. Acta Universitatis Palackianae Olomucensis. Gymnica, 41(1), 43-50. 
Cohen, D. J., \& Crabtree, B. F. (2008). Evaluative criteria for qualitative research in health care: controversies and recommendations. The Annals of Family Medicine, 6(4), 331-339.

Comprehensive Service member Fitness Program. (n.d.). Retrieved from http://csf2.army.mil/about.html

Continuation on Active Duty. (n.d.). Retrieved from http://www.armyg1.army.mil/docs/COAR_RADS_Brief_(9\%20APR\%2009).pdf

Crawford, J. J., Gayman, A. M., \& Tracey, J. (2014). An examination of post-traumatic growth in Canadian and American ParaSport athletes with acquired spinal cord injury. Psychology Of Sport And Exercise, 15(4), 399-406.

doi:10.1016/j.psychsport.2014.03.008

Danish, S. J., \& Antonides, B. J. (2013). The challenges of reintegration for service members and their families. American Journal Of Orthopsychiatry, 83(4), 550558. doi:10.1111/ajop.12054

Day, M. (2013). The role of initial physical activity experiences in promoting posttraumatic growth in Paralympic athletes with an acquired disability. Disability And Rehabilitation: An International, Multidisciplinary Journal, 35(24), 20642072. doi:10.3109/09638288.2013.805822

Defense Manpower Data Center. (2013). Retrieved from https://www.dmdc.osd.mil/appj/dwp/dwp_reports.jsp Department of Defense. (2010). Report on the Impact of Deployment of Members of the Armed Forces on Their Dependent Children. Retrieved from http://www.militaryonesource.mil/12038/MOS/Reports/Report-to-Congress-on- 
Impact-of-Deployment-on-Military-Children.pdf

Department of Health and Human Services, W. C. (2000). Healthy People 2010:

Conference Edition, Volume I [and] Volume II.

Dyck, C. B. (2011). Football and Post-War Reintegration: exploring the role of sport in DDR processes in Sierra Leone. Third World Quarterly, 32(3), 395-415.

doi:10.1080/01436597.2011.573936

Fann, J. R., Hart, T., \& Schomer, K. G. (2009). Treatment for depression after traumatic brain injury: A systematic review. Journal Of Neurotrauma, 26(12), 2383-2402. doi:10.1089/neu.2009.1091

Fox, K. R., \& Corbin, C. B. (1989). The physical self-perception profile: Development and preliminary validation. Journal of Sport \& Exercise Psychology.

Gecas, V., \& Burke, P. J. (1995). Self and identity. Sociological perspectives on social psychology, 41-67.

Gill, D. L., Deeter, T. E., Smith, D. D., \& Stewart, S. S. (2003). Sport Orientation Questionnaire. Journal Of Sport Behavior, 26(4), 384-395.

Goodwin, G. (2008). Psychology in sports and the military: building understanding and collaboration across disciplines. Military Psychology (Taylor \& Francis Ltd), 20, S147-53.

Hancock, K. M., Craig, A. R., Dickson, H. G., Chang, E., \& Martin, J. (1993). Anxiety and depression over the first year of spinal cord injury: a longitudinal study. Spinal Cord, 31(6), 349-357. 
Hahn, J., Aronow, H., Rosario, E. R., \& Guenther, N. (2013). Multidimensional health risk appraisal among adults aging with acquired disabilities. Disability and Health Journal, 6(3), 195-203. doi:10.1016/j.dhjo.2013.02.002

Hammermeister, J., Pickering, M., McGraw, L., \& Ohlson, C. (2010). Relationship Between Psychological Skill Profiles and Service member Physical Fitness Performance. Military Psychology (Taylor \& Francis Ltd), 22(4), 399-411. doi:10.1080/08995605.2010.513238

Hawkins, B. L., Cory, A., \& Crowe, B. M. (2011). Effects of Participation in a Paralympic Military Sports Camp on Injured Service Members: Implications for Theraputic Recreation. Therapeutic Recreation Journal, 45(4), 309-325.

Hibbard, M. R., Uysal, S., Sliwinski, M., \& Gordon, W. (1998). Undiagnosed health issues in individuals with traumatic brain injury living in the community. The Journal of head trauma rehabilitation, 13(4), 47-57.

Hutzter, Y., \& Bar-Eli, M. (1993). Psychological benefits of sports for disabled people: A review. Scandinavian journal of medicine \& science in sports, 3(4), 217-228.

Jefferies, P., Gallagher, P., \& Dunne, S. (2012). The Paralympic athlete: a systematic review of the psychosocial literature. Prosthetics And Orthotics International, 36(3), 278-289. doi:10.1177/0309364612450184

Kavanagh, E. (2012). Affirmation through disability: one athlete's personal journey to the London Paralympic Games. Perspectives In Public Health, 132(2), 68-74.

Kingsbury, A. (2010). The Military Option. U.S. News \& World Report, 147(10), 40-43.

Larner, S. (2005). Common psychological challenges for patients with newly acquired disability. Nursing Standard, 19(28), 33-39. 
Li, L., \& Moore, D. (1998). Acceptance of Disability and Its Correlates. Journal Of Social Psychology, 138(1), 13-25.

Lundberg, N., Bennett, J., \& Smith, S. (2011). Outcomes of Adaptive Sports and Recreation Participation among Veterans Returning from Combat with Acquired Disability. Therapeutic Recreation Journal, 45(2), 105-120.

Machida, M., Irwin, B., \& Feltz, D. (2013). Resilience in Competitive Athletes With Spinal Cord Injury: The Role of Sport Participation. Qualitative Health Research, 23(8), 1054-1065. doi:10.1177/1049732313493673

Marsh, H. W., Hey, J., Roche, L. A., \& Perry, C. (1997). Structure of physical selfconcept: Elite athletes and physical education students. Journal of Educational Psychology, 89(2), 369.

Martin, J., Adams-Mushett, C., \& Smith, K. (1995). Athletic identity and sport orientation of adolescent swimmers with disabilities. Adapted Physical Activity Quarterly, 12(2), 113-123.

Martin Ginis, K., Jetha, A., Mack, D., \& Hetz, S. (2010). Physical activity and subjective well-being among people with spinal cord injury: a meta-analysis. Spinal Cord, 48(1), 65-72. doi:10.1038/sc.2009.87

Molik, B., Zubala, T., Słyk, K., Bigas, G., Gryglewicz, A., \& Kucharczyk, B. (2010). Motivation of the disabled to participate in chosen Paralympics events (wheelchair basketball, wheelchair rugby, and boccia). Physiotherapy, 18(1), 4251. 
Murphy, N. A., \& Carbone, P. S. (2008). Promoting the Participation of Children With Disabilities in Sports, Recreation, and Physical Activities. Pediatrics, 121(5), 1057-1061. doi:10.1542/peds.2008-0566

Neuendorf, K.A., 2002. The content analysis guidebook. Thousand Oaks, CA: Sage.

Osran, H. C., Smee, D. E., Sreenivasan, S., \& Weinberger, L. E. (2010). Living outside the wire: Toward a transpersonal resilience approach for OIF/OEF veterans transitioning to civilian life. Journal Of Transpersonal Psychology, 42(2), 209235.

Page, S. J., O'Connor, E., \& Peterson, K. (2001). Leaving the disability ghetto. Journal Of Sport \& Social Issues, 25(1), 40-55.

Paterson, B., \& Scott-Findlay, S. (2002). Critical issues in interviewing people with traumatic brain injury. Qualitative Health Research, 12(3), 399-409.

Patton, M. (2002). Qualitative evaluation and research methods. Thousand Oaks, CA: Sage Publications.

Perrier, M., Smith, B., Strachan, S. M., \& Latimer-Cheung, A. E. (2014). Narratives of Athletic Identity After Acquiring a Permanent Physical Disability. Adapted Physical Activity Quarterly, 31(2), 106-124.

Perrier, M., Sweet, S. N., Strachan, S. M., \& Latimer-Cheung, A. E. (2012). I act, therefore I am: Athletic identity and the health action process approach predict sport participation among individuals with acquired physical disabilities. Psychology of Sport \& Exercise, 13(6), 713-720. 
Pew Research Center. (2011). Military-civilian gap: War and sacrifice in the post 9/11

era. Retrieved from http://www.pewsocialtrends.org/2011/10/05/war-andsacrifice-in-the-post-911-era/

Ravesloot, C., Seekins, T., \& Walsh, J. (1997). A structural analysis of secondary conditions experienced by people with physical disabilities. Rehabilitation Psychology, 42(1), 3-16. doi:10.1037/0090-5550.42.1.3

Ryan, R. M., \& Deci, E. L. (2012). Multiple identities within a single self: A selfdetermination theory perspective on internalization within contexts and cultures. In M. R. Leary, J. P. Tangney, M. R. Leary, J. P. Tangney (Eds.), Handbook of self and identity (2nd ed.) (pp. 225-246). New York, NY, US: Guilford Press.

Rydstedt, L. W., \& Österberg, J. (2013). Psychological characteristics of Swedish mandatory enlisted service members volunteering and not volunteering for international missions: An exploratory study. Psychological Reports, 112(2), 678688.

Rolls, C., Inglis, A., \& Kristy, S. (1997). Study abroad programs: creating awareness of and changing attitudes to nursing, health and ways of living in other cultures. Contemporary nurse, 6(3-4), 152-156.

Salick, E. C., \& Auerbach, C. F. (2006). From devastation to integration: Adjusting to and growing from medical trauma. Qualitative Health Research, 16(8), 10211037.

Sherrill, C. C. (1997). Disability, identity, and involvement in sport and exercise. In , In, Fox, K.R. (ed.), The physical self: from motivation to well-being, Champaign, Ill., Human Kinetics Publishers, 1997, p. 257-286. 
Smith, R. T., \& True, G. (2014). Warring Identities Identity Conflict and the Mental Distress of American Veterans of the Wars in Iraq and Afghanistan. Society and Mental Health, doi: 2156869313512212

Super, J. R. (1992). Self-concept and need for achievement of men with physical disabilities. Journal Of General Psychology, 119(1), 73.

Tedeschi, R. G., \& McNally, R. J. (2011). Can we facilitate posttraumatic growth in combat veterans?. American Psychologist, 66(1), 19-24. doi:10.1037/a0021896

Thoits, P. A. (1992). Identity Structures and Psychological Well-Being: Gender and Marital Status Comparisons. Social Psychology Quarterly, 55(3), 236-256.

Thoits, P. A. (2013). Self, identity, stress, and mental health. In C. S. Aneshensel, J. C. Phelan, A. Bierman (Eds.), Handbook of the sociology of mental health (2nd ed.) (pp. 357-377). New York, NY, US: Springer Science + Business Media.

Thoits, P. A. (2013). Volunteer identity salience, role enactment, and well-being: Comparisons of three salience constructs. Social Psychology Quarterly, 76(4), 373-398. doi:10.1177/0190272513498397

Thoits, P. A., \& Virshup, L. K. (1997). Me's and we's. Self and identity: Fundamental issues, 106-133.

Toblin, R. L., Riviere, L. A., Thomas, J. L., Adler, A. B., Kok, B. C., \& Hoge, C. W. (2012). Grief and physical health outcomes in U.S. service members returning from combat. Journal Of Affective Disorders, 136(3), 469-475. doi:10.1016/j.jad.2011.10.048

U.S. Paralympics, (n.d.). U.S. Paralympics Military. Retrieved from http://www.teamusa.org/us-paralympics/military 
Van de Vliet, P., Van Biesen, D., \& Vanlandewijck, Y. C. (2008). Athletic identity and self-esteem in Flemish athletes with a disability. European Journal of Adapted Physical Activity, 1(1), 9-21.

Van Slyke, J. (n.d.). Post Traumatic Growth. Naval Center for Combat \& Operational Stress Control. Retrieved from http://www.med.navy.mil/sites/nmcsd/nccosc/healthProfessionalsV2/reports/Docume nts/PTG_WhitePaperFinal.pdf

Vest, B. M. (2013). Citizen, Service member, or Citizen-Service member? Negotiating Identity in the US National Guard. Armed Forces \& Society (0095327X), 39(4), 602-627. doi:10.1177/0095327X12457725

Weisskopf, M. (2007). A grim milestone: 500 amputees. Retrieved from http://content.time.com/time/nation/article/0,8599,1580531,00.html

Williams, A., Ericsson, K., Ward, P., \& Eccles, D. (2008). Research on expertise in sport: implications for the military. Military Psychology (Taylor \& Francis Ltd), 20S123-45.

Wright, B. A. (1983). Physical disability-a psychosocial approach. HarperCollins Publishers.

World Class Athlete Program. (n.d.). Retrieved from http://www.thearmywcap.com/\#!paralympics/c1viv 


\section{Appendix B}

\section{Recruitment Script 1: Invitation to Participate Letter}

\section{Dear Potential Participant,}

This letter is a request for you to take part in a research project to explore the influence of participation in an elite Paralympic military sport program has on the (re)establishment of identity post injury by drawing upon the life experiences of the TSU Paralympic section unit members.

This study is being conducted by Lindsay Hammond, M.S. under the supervision of Dr. Kristen Dieffenbach, an associate professor in the College of Physical Activity and Sport Sciences, in partial fulfillment of the requirements for a doctorate degree in Coaching and Teaching Studies. The study includes participating in three, 30 minute long in-person interviews.

The interviews for this study will be audio recorded, and all information will be kept confidential and stored on a password-protected file. If a publication results from this study, neither your name nor any other information that may identify you will be published. Participation in this interview process is completely voluntary and you can withdraw from the study at any point. You can also skip any of the questions you do not want to answer. This study has been reviewed and I have received permission to conduct it from West Virginia University's Institutional Review Board (Protocol \#1409434316). For questions regarding this protocol, you can reach WVU's Office of Research Integrity and Compliance at (304) 293-7073.

If you would like be a participant, please respond to by email at your earliest convenience. Upon agreement to participate, an interview schedule will be created and you will be notified of specific interview times and locations. Additionally, a formal letter of consent will be distributed at the first interview.

Your participation in this study would be greatly appreciated! If you have any questions or concerns, please feel free to contact my advisor, Dr. Kristen Dieffenbach or me.

Sincerely,

Lindsay M. Hammond, M.S.

Primary Investigator

West Virginia University

Dept. of Coaching and Teaching Studies

Lindsay.brooke@mail.wvu.edu

859-582-4547
Dr. Kristen Dieffenbach, PhD

Dissertation Chair

West Virginia University

Dept. of Coaching and Teaching Studies

Kristen.Dieffenbach@mail.wvu.edu

304-293-0847 


\section{Appendix C}

\section{Script and Guide for Participant Interview \#1}

Hello, my name is Lindsay Hammond and I am conducting this research as a requirement for completion of my doctoral studies. Thank you so much for taking the time to speak with me today. Over the next three days, we will meet each day for approximately 30 minutes. The purpose of these discussions is to gain a better understanding of your experiences of participating in the TSU Paralympic Section.

During the interview today, you will be asked to share your personal experiences related to joining the military, guided by my questions and prompts. This discussion will be audiotaped, but please know all information will be kept confidential and stored on a password protected file. If any publication results from this study, neither your name nor any other information that may identify you will be published. During our discussion, I will be making notes based on your responses. Participation in this interview process is completely voluntary and you can withdraw from the study at any point. You can also skip any of the questions you do not want to answer. Additionally, as an extra precaution, cards with the contact information for the Veteran's Crisis Services are here for you, as well as a list of counseling support services in the local vicinity. Feel free to take any of these with you.

This study has been reviewed and I have received permission to conduct it from West Virginia University's Institutional Review Board (Protocol \#1409434316). Do you have any questions before we begin? 
Interview Guide \#1: Service Member Identity ${ }^{1}$

1. Tell me about your experience joining the military.

Probes:

Why did you join? What inspired you to join?

How did your friends and family feel about your decision?

Describe yourself prior to enlistment.

What role or MOS were you most interested in when joining?

2. Tell me about your experience in the military.

Probes:

What was your role or roles within the military?

Can you describe what your responsibilities entailed?

How would you describe yourself in this role?

3. Tell me about deployment experience(s).

Probes:

Describe yourself within the deployment environment.

Did your role or responsibilities change during deployment? Describe.

Did you see yourself any differently or your role within the military differently after deployment? Describe.

${ }^{1}$ Interview guides were reviewed by Dr. Ashley Bittle, Clinical Psychologist and Team Chief, Ft. Carson Military Base, Colorado Springs, CO. 


\section{Appendix D}

\section{Script and Guide for Participant Interview \#2}

Hello, thank you so much for taking the time to meet with me again today.

During the interview today, you will be asked to share your personal experiences related being assigned to the TSU Paralympic section. This discussion will again be guided through my questions and prompts. Similarly to yesterday, this discussion will be audiotaped and all information will be kept confidential and stored on a passwordprotected file. If any publication results from this study, neither your name nor any other information that may identify you will be published. During our discussion, I will be making notes based on your responses. Participation in this interview process is completely voluntary and you can withdraw from the study at any point. Additionally, as an extra precaution, cards with the contact information for the Veteran's Crisis Services are here for you, as well as a list of counseling support services in the local vicinity. Feel free to take any of these with you.

This study has been reviewed and I have received permission to conduct it from West Virginia University's Institutional Review Board (Protocol \#1409434316). Do you have any questions before we begin? 
Interview Guide \#2: Athletic/Service Member Identity ${ }^{2}$

1. Tell me about being apart of the TSU Paralympic section.

Probes:

What attracted you to this unit?

What is your role/responsibilities in the unit?

Describe the unit environment and expectations.

How would you best describe yourself within this unit?

2. What is it like to train for the Paralympics as apart of the military?

Probes:

How did you get involved with shooting sports?

How did you get involved with Paralympic sport?

What does it take to be a Paralympic shooter?

What are your personal aspirations?

What drives you to aspire to achieve these personal goals?

3. Describe who you are today.

Probes:

Do you see yourself as an athlete, service member, athlete-service member or service member-athlete or other? Why?

How would your friends and family describe you?

What is life like outside the unit?

4. Who are your biggest supporters/champions? Why?

${ }^{2}$ Interview guides were reviewed by Dr. Ashley Bittle, Clinical Psychologist and Team Chief, Ft. Carson Military Base, Colorado Springs, CO. 


\section{Appendix E}

\section{Script and Guide for Participant Interview \#3}

Hello, thank you so much for taking the time to meet with me again today.

During the interview today, you will be asked to share your personal experiences related to the transition period from joining the military to acquiring a disability/injury in combat to where you are now, at the TSU.

This discussion will again be guided through my questions and prompts. Similarly to yesterday, this discussion will be audiotaped and all information will be kept confidential and stored on a password-protected file. If any publication results from this study, neither your name nor any other information that may identify you will be published. During our discussion, I will be making notes based on your responses.

Participation in this interview process is completely voluntary and you can withdraw from the study at any point. You can also skip any of the questions you do not want to answer. Additionally, as an extra precaution, cards with the contact information for the Veteran's Crisis Services are here for you, as well as a list of counseling support services in the local vicinity. Feel free to take any of these with you.

This study has been reviewed and I have received permission to conduct it from West Virginia University's Institutional Review Board (Protocol \#1409434316). Do you have any questions before we begin? 
Interview Guide \#3: Transformative Experiences ${ }^{3}$

1. In our previous interview discussions we discussed joining the military and also the TSU. Can you tell me about the memorable experiences (good or bad) that took place between those two points in time that have influenced who you are today?

Probes:

Was there a certain person who inspired you?

Was there any point in time when you felt you were no longer a service member? Did you feel prepared/supported for life challenges and changes associated with acquiring a physical disability?

2. Can you talk briefly about a little bit about your personal rehabilitation journey?

Probes:

How did your friends and family help in the process?

When was sport introduced? Who introduced it? What sports were introduced? How did sport help with the rehabilitation and/or reintegration process? When and why did you decide you wanted to apply for RADS status? Are you satisfied with your current MOS? 


\section{Appendix F}

\section{Recruitment Script 2: Invitation to Participate E-Mail}

Hello , my name is Lindsay Hammond, M.S. and I am currently a $4^{\text {th }}$ year Ph.D. candidate in the Coaching and Teaching Studies program at West Virginia University, studying under Dr. Kristen Dieffenbach. I am actively recruiting participants for my dissertation study on the members of the Target Sports Unit Paralympic section. The purpose of my study is to explore the influence of participation in an elite military sport program has on the (re)establishment of identity post injury by drawing upon the life experiences of the TSU Paralympic section unit members. The study includes participating in three, 30 minute long in-person interviews.

The interviews for this study will be audio recorded, and all information will be kept confidential and stored on a password-protected file. If a publication results from this study, neither your name nor any other information that may identify you will be published. Participation in this interview process is completely voluntary and you can withdraw from the study at any point. You can also skip any of the questions you do not want to answer. This study has been reviewed and I have received permission to conduct it from West Virginia University's Institutional Review Board (Protocol \#1409434316). For questions regarding this protocol, you can reach WVU's Office of Research Integrity and Compliance at (304) 293-7073.

If you would like be a participant, please respond to this email at your earliest convenience. Upon agreement to participate, an interview schedule will be created and you will be notified of specific interview times and locations. Additionally, a formal letter of consent will be distributed at the first interview.

Your participation in this study would be greatly appreciated! If you have any questions or concerns, please feel free to contact my advisor, Dr. Kristen Dieffenbach or myself.

Thank you,

Lindsay M. Hammond, M.S.

Primary Investigator

West Virginia University

Dept. of Coaching and Teaching Studies

Lindsay.brooke@mail.wvu.edu

859-582-4547
Dr. Kristen Dieffenbach, PhD

Dissertation Chair

West Virginia University

Dept. of Coaching and Teaching Studies

Kristen.Dieffenbach@mail.wvu.edu

304-293-0847 


\section{Appendix G \\ Only Minimal Risk \\ Consent Information Form (without HIPAA)}

\author{
Principal Investigator \\ Department \\ Protocol Number \\ Study Title \\ Co-Investigator(s) \\ Sponsor (if any)
}

\author{
Dr. Kristen Dieffenbach \\ Coaching and Teaching Studies \\ 1409434316 \\ Re-establishing Identity Through Sport \\ Lindsay Hammond \\ Click here to enter text.
}

\section{Contact Persons}

In the event you experience any side effects or injury related to this research, you should contact Dr. Kristen Dieffenbach at (304) 293-0874. (After hours contact: Dr. Dieffenbach at (301) 697-1142). If you have any questions, concerns, or complaints about this research, you can contact Dr. Kristen Dieffenbach at (304) 293-0874.

For information regarding your rights as a research subject, to discuss problems, concerns, or suggestions related to the research, to obtain information or offer input about the research, contact the Office of Research Integrity \& Compliance at (304) 293-7073.

In addition if you would like to discuss problems, concerns, have suggestions related to research, or would like to offer input about the research, contact the Office of Research Integrity and Compliance at 304-293-7073.

\section{Introduction}

You, , have been asked to participate in this research study, which has

been explained to you by . This

study is being conducted by Dr. Kristen Dieffenbach and Lindsay Hammond in the Department of Coaching and Teaching Studies at West Virginia University.

\section{Purpose(s) of the Study}

The purpose of the study is to explore the influence of participation in an elite Paralympic military sport program has on the (re)establishment of identity post injury by drawing upon the life experiences of the TSU Paralympic section unit members.

\section{Description of Procedures}

The study includes participating in three, 30 minute long in-person interviews.

The interviews for this study will be audio recorded, and all information will be kept confidential and stored on a password-protected file. If a publication results from this study, neither your name nor any other information that may identify you will be published. Participation in this interview process is completely voluntary and you can withdraw from the study at any point. You can also skip any of the questions you do not want to answer.

\section{Discomforts}

There are no known or expected risks from participating in this study, except for the mild frustration associated with answering the questions. 


\begin{abstract}
Alternatives
You do not have to participate in this study.

Alternatives that could be considered in your case include:
\end{abstract}

\title{
Benefits
}

You may not receive any direct benefit from this study. The knowledge gained from this study may eventually benefit others.

\section{Financial Considerations}

There are no special fees for participating in this study. [If planning to pay participants, explain fully and clearly any fees or bonuses and how they will be paid, including proration. Unless the study is confidential, the WVU consent form must inform subjects that they will be asked to provide their Social Security Number and verification of U.S Citizenship or Permanent Resident Status to receive payment. For confidential studies only name and address are required.]

\section{Confidentiality}

Any information about you that is obtained as a result of your participation in this research will be kept as confidential as legally possible. Your research records and test results, just like hospital records, may be subpoenaed by court order or may be inspected by the study sponsor or federal regulatory authorities (including the FDA if applicable) without your additional consent.

In addition, there are certain instances where the researcher is legally required to give information to the appropriate authorities. These would include mandatory reporting of infectious diseases, mandatory reporting of information about behavior that is imminently dangerous to your child or to others, such as suicide, child abuse, etc.

Audiotapes or videotapes will be kept locked up and will be destroyed as soon as possible after the research is finished. In any publications that result from this research, neither your name nor any information from which you might be identified will be published without your consent.

\section{Voluntary Participation}

Participation in this study is voluntary. You are free to withdraw your consent to participate in this study at any time.

Refusal to participate or withdrawal will involve no penalty to you.

In the event new information becomes available that may affect your willingness to participate in this study, this information will be given to you so that you can make an informed decision about whether or not to continue your participation.

You have been given the opportunity to ask questions about the research, and you have received answers concerning areas you did not understand.

Upon signing this form, you will receive a copy. 
I willingly consent to participate in this research.

Signature of Subject

Printed Name

Date

Time

The participant has had the opportunity to have questions addressed. The participant willingly agrees to be in the study.

Signature of Investigator or Co-Investigator

Printed Name

Date

Time 